\title{
COVID-19 Infection and Circulating Microparticles-Reviewing Evidence as Microthrombogenic Risk Factor for Cerebral Small Vessel Disease
}

\author{
Che Mohd Nasril Che Mohd Nassir ${ }^{1}$ (1) $\cdot$ Sabarisah Hashim ${ }^{1,2} \cdot$ Kah Keng Wong $^{2,3}$ (D) Sanihah Abdul Halim ${ }^{2,4}$ (D) \\ Nur Suhaila Idris ${ }^{2,5}$ (D) Nanthini Jayabalan ${ }^{6}(\mathbb{D}) \cdot$ Dazhi Guo $^{7}(\mathbb{D}) \cdot$ Muzaimi Mustapha $^{1,2} \mathbb{I D}^{\circ}$
}

Received: 25 November 2020 / Accepted: 16 June 2021 / Published online: 26 June 2021

(c) The Author(s) 2021

\begin{abstract}
Severe acute respiratory syndrome corona virus-2 (SARS-CoV-2) due to novel coronavirus disease 2019 (COVID-19) has affected the global society in numerous unprecedented ways, with considerable morbidity and mortality. Both direct and indirect consequences from COVID-19 infection are recognized to give rise to cardio- and cerebrovascular complications. Despite current limited knowledge on COVID-19 pathogenesis, inflammation, endothelial dysfunction, and coagulopathy appear to play critical roles in COVID-19-associated cerebrovascular disease (CVD). One of the major subtypes of CVD is cerebral small vessel disease (CSVD) which represents a spectrum of pathological processes of various etiologies affecting the brain microcirculation that can trigger subsequent neuroinflammation and neurodegeneration. Prevalent with aging, CSVD is a recognized risk factor for stroke, vascular dementia, and Alzheimer's disease. In the background of COVID-19 infection, the heightened cellular activations from inflammations and oxidative stress may result in elevated levels of microthrombogenic extracellular-derived circulating microparticles (MPs). Consequently, MPs could act as pro-coagulant risk factor that may serve as microthrombi for the vulnerable microcirculation in the brain leading to CSVD manifestations. This review aims to appraise the accumulating body of evidence on the plausible impact of COVID-19 infection on the formation of microthrombogenic MPs that could lead to microthrombosis in CSVD manifestations, including occult CSVD which may last well beyond the pandemic era.
\end{abstract}

Keywords COVID-19 $\cdot$ Coagulopathy $\cdot$ Microparticles $\cdot$ Cerebral small vessel disease $\cdot$ Stroke

Muzaimi Mustapha

mmuzaimi@usm.my

1 Department of Neurosciences, School of Medical Sciences, Universiti Sains Malaysia, Health Campus, 16150 Kubang Kerian, Kelantan, Malaysia

2 Hospital Universiti Sains Malaysia, 16150 Kubang Kerian, Kelantan, Malaysia

3 Department of Immunology, School of Medical Sciences, Universiti Sains Malaysia, Health Campus, 16150 Kubang Kerian, Kelantan, Malaysia

4 Department of Internal Medicine, School of Medical Sciences, Universiti Sains Malaysia, Health Campus, 16150 Kubang Kerian, Kelantan, Malaysia
5 Department of Family Medicine, School of Medical Sciences, Universiti Sains Malaysia, Health Campus, 16150 Kubang Kerian, Kelantan, Malaysia

6 Translational Neuroscience Lab, UQ Centre for Clinical Research, the University of Queensland, Herston, Brisbane 4029, Australia

Department of Hyperbaric Oxygen, The Sixth Medical Center of PLA General Hospital, 6 Fucheng Rd, Beijing 100048, China 


\section{Introduction}

In 2020, the world is battling a pandemic caused by a novel coronavirus disease 2019 (COVID-19). The first appeared in Wuhan, China, in December 2019 with 41 cases of atypical pneumonia; it was not until early January 2020 that these cases were confirmed as an infection attributed to COVID-19 [1]. The pneumonia it caused was later named as severe acute respiratory syndrome coronavirus-2 (SARS-CoV-2) [2]. By early March 2020, COVID-19 has been declared as a pandemic by the World Health Organization (WHO), and to date, it remains unabated worldwide surpassing 100 million cases and over two million deaths as on 15 January 2021 [3]. The clinical manifestations of COVID-19 and the disease course are erratic, ranging from asymptomatic to mild respiratory infections, pneumonia to acute respiratory distress syndrome (ARDS), and even death [4, 5]. At present, we have no definitive treatment for COVID-19, while concerted global efforts are well in progress [6]. Given that our present knowledge of COVID-19 and SARS-CoV-2 is still expanding, most countries are currently putting their best efforts by implementing preventive and control strategies to break the chain of COVID-19 infection.

Beyond the pulmonary manifestations, both direct and indirect consequences from COVID-19 infection are known to cause cardio- and cerebrovascular complications [7]. Despite current limited knowledge on COVID19 pathogenesis, inflammation, endothelial dysfunction, and coagulopathy appear to play critical roles in COVID19-associated acute cerebrovascular disease (CVD) [8, 9]. One of the major subtypes of CVD is cerebral small vessel disease (CSVD) which represents a spectrum of pathological processes of various etiologies affecting the brain microcirculation that can trigger subsequent neuroinflammation and neurodegeneration. Prevalent with aging, CSVD is a recognized risk factor for stroke, vascular dementia, and Alzheimer's disease (AD) [10, 11]. In the background of COVID-19 infection, the known heightened cellular activation from inflammation and oxidative stress may result in elevated levels of microthrombogenic extracellular-derived circulating microparticles (MPs). Consequently, MPs could act as pro-coagulant risk factor that could serve as microthrombi for the vulnerable microcirculation in the brain leading to recognized CSVD manifestations [12, 13], i.e., from asymptomatic (occult) to symptomatic (typical lacunar stroke).

Hence, this review aims to appraise the accumulating body of evidence on the plausible impacts of COVID-19 on the formation of microthrombogenic MPs that could lead to microthrombosis in CSVD manifestations, including occult CSVD which may last well beyond the pandemic era.

\section{Characteristic of COVID-19}

The family Coronaviridae are large, enveloped viruses with a positive sense ribonucleic acid (RNA) genome that can infect both animals and humans. These coronaviruses may resemble one another in terms of their pathogenesis and pathological features and even share similar clinical manifestations [14]. Bats are widely viewed as its reservoir, while Malayan pangolins (Manis javanica) is thought to be the intermediate host to facilitate the zoonotic transfer to humans [15].

According to the International Committee on Taxonomy of Viruses, SARS-CoV-2 belongs to a member of the genus Betacoronavirus [16] that can cause multi-system clinical manifestations involving respiratory, enteric, hepatobiliary, and nervous systems [17]. SARS-CoV-2 has now proven itself as a highly pathogenic coronavirus to infect human populations. Two other members of this family, the severe acute respiratory syndrome coronavirus (SARS-CoV) and Middle East respiratory syndrome coronavirus (MERS$\mathrm{CoV}$ ), had previously resulted in significant global outbreaks in 2002 and 2012, respectively [18], though not to the scale of a pandemic. SARS-CoV-2 is genetically distinct from SARS-CoV (near 79\% similarity) and MERS-CoV (near 50\% similarity) [1]. Structurally, SARS-CoV-2 RNA encodes four principal proteins: one nucleocapsid protein surrounding the RNA genome and three membrane proteins, the spike glycoprotein $(\mathrm{S})$ with $\mathrm{S} 1$ and $\mathrm{S} 2$ domains, the matrix glycoprotein, and the envelope protein [19].

\section{The Virology of COVID-19}

During the initial phase of the infection, the virus infiltrates and proliferates in the lung parenchyma. Upon entry into the respiratory tract, the virus targets the surfactant-producing, alveolar epithelial type 2 (AT2) cells. Surfactant decreases the surface tension within alveoli to reduce airway collapse. This early phase is characterized clinically by mild constitutional symptoms as the virus releases inflammatory mediators to stimulate monocyte/macrophage infiltration as the innate immune system initial response [20].

The entry into the AT2 cell is mediated by S glycoprotein interaction with the host angiotensin converting enzyme 2 (ACE2) receptor [21] (Fig. 1). Of note, ACE2 receptors can also be found in the kidney, heart, gut, pancreas, and endothelial cells (ECs) [22]. In normal physiology, ACE2 helps to regulate the blood pressure via inhibition of the angiotensin renin-aldosterone pathways [23]. However, elevated level of angiotensin II has been associated with vasoconstriction oxidative process and apoptosis that lead to neurodegeneration and age-related degenerative disease [24]. The S1 domain facilitates the virus-receptor binding, while 


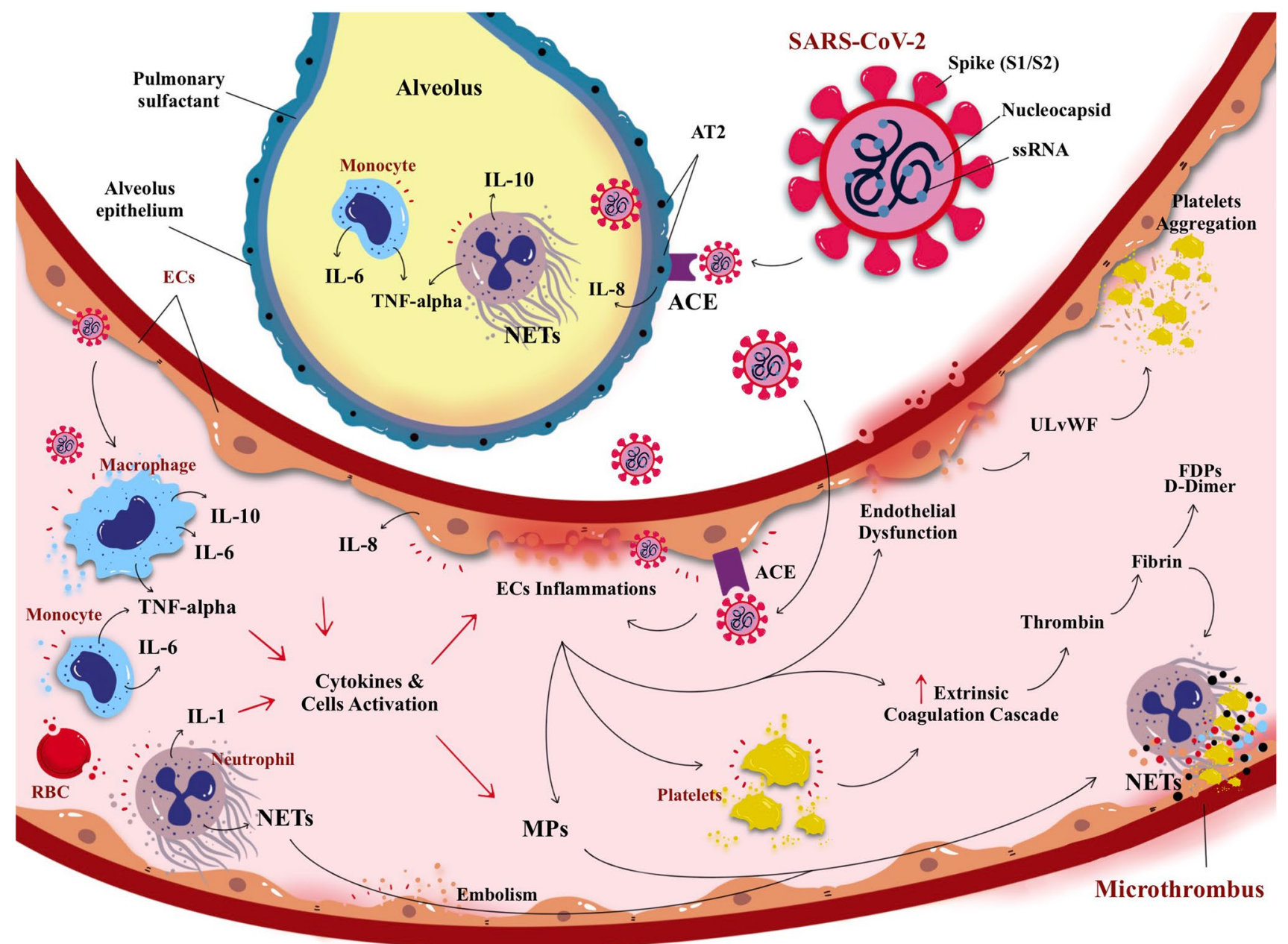

Fig. 1 A schematic illustration of direct SARS-CoV-2 infection from the lung alveolus and blood circulation. The virus SARS-CoV-2 (and its main structure) acquired through respiratory droplets attacking angiotensin converting enzymes (ACE) type 2 receptors that are present on the surface of alveolus epithelium, namely, the alveolar epithelial type (AT2). The attachment of SARS-CoV-2 with ACE elicited the inflammatory reaction of the AT2 cells, releasing proinflammatory cytokines; i.e., interleukin-8 (IL-8) alongside the activation of monocytes and neutrophil elevate the inflammation causing lung parenchymal injury. In addition, SARS-CoV-2 also can enter

the $\mathrm{S} 2$ domain causes fusion of the viral RNA with the cell membrane [24]. Notably, the CoV S protein is cleaved by a group of serine proteases, including elastase, cathepsins, trypsin, type 2 transmembrane serine protease (TMPRSS2) [20], and integrins that enable invasion into the epithelial cells [25]. On this basis, the use of chloroquine and hydroxychloroquine is linked to their ability to increase endosomal $\mathrm{pH}$ which can prevent ACE2 separation from SARS-CoV-2 [26] and, hence, guard against an intracellular virus diffusion. The anti-viral drugs (remdesivir, ribavirin, favipiravir, umifenovir, lopinavir/ritonavir) interfere with RNA processing steps to arrest the viral replication [27]. Furthermore, neutralizing antibodies from those who recovered from blood circulation and raise activation of circulating cells (i.e., macrophage, monocytes, platelets, and neutrophil) to release pro-inflammatory cytokines causing endothelial inflammation (endotheliitis). Endotheliitis then activates the coagulation cascade and production of thrombin followed by fibrinolysis and fibrin. If left untreated, the infection will progress to cause hypercoagulation state leading to coagulopathy. Collectively, cytokines, cellular activation, and endothelial inflammation drive the production of microparticles (MPs) which further instigate the production of microthrombus, cellendothelium adhesion, and aggregation 0

COVID-19 had resulted in reduction of the viral loads [28]. Meanwhile, candidate vaccines with promising leads include adenovirus recombinant vectors, type 26 (rAd26) and type 5 (rAd5) carrying the gene for SARS-CoV-2 spike glycoprotein (rAd26-S and rAd5-S) and the chimpanzee adenovirusvectored vaccine (ChAdOx $1 \mathrm{nCoV}$-19) (Oxford University/ AstraZeneca) expressing the SARS-CoV-2 spike protein [29, 30]. Moreover, two encapsulated RNA-based vaccines have been proven effective including mRNA-1273 (Moderna) with 94.1\% efficacy [31] and BNT162b2 (Pfizer/BioNTech) with $95 \%$ efficacy [32] with emergence use approvals by regulatory bodies in over 70 countries worldwide to date and counting. Aside from vaccines, there are also efforts 
to synthesize recombinant immunoglobulins to mimic the endogenous, neutralizing antibodies [19]. Numerous clinical trials are also underway that target antiprotease activities, including the plasmin(ogen) inhibitor, tranexamic acid, or TMPRSS2 antagonist (camostat mesylate and nafomastat) [33].

\section{Clinico-pathological Features of COVID-19}

COVID-19 affects all ages with adult predominance [4]. The established risk factors include age greater than 65 years, diabetes mellitus (i.e., type 2 diabetes mellitus, T2DM) and hypertension in nearly $40 \%$ of cases [7]. The advocated physical distancing is a measure to minimize human-tohuman transmission that can occur through droplets from the infected respiratory tract which can reach up to $2 \mathrm{~m}$ from a sneeze or a cough of an infected person [34]. The average incubation period is between 1 and 14 days [33], with up to $25 \%$ of those tested positives for COVID-19 that are asymptomatic $[5,35]$. Upon entry across the mucous membranes (nose and/or larynx), COVID-19 viruses can track its way to reach the lung parenchyma and subsequently result in viremia once in the systemic circulatory system resulting in a widespread hyperinflammation (Fig. 1). The commonest symptoms include fever, dry cough, dyspnea, ageusia, anosmia, myalgias, and/or fatigue [36]. Majority of cases would also have radiological evidence pneumonic changes [37]. Hence, the infected persons could worsen clinically, between 7 and 14 days after the onset [38].

Based on the current targeted therapies for COVID-19 cases that correspond to some extent with the evolving pathophysiological processes, the infection has been proposed to constitute three key phases [39, 40]: The first phase involves viral replication and manifests with mild symptoms (viremia phase); the second phase features adaptive immunity stimulation and more prominent respiratory symptoms (pneumonic phase); and the last phase, in severe cases, is characterized by a hyperinflammation phase (Fig. 2). However, overlaps do exist between these phases in individual patients. In general, individuals with competent immune functions and without notable risk factors may effectively suppress the virus in the first and/or second phase. However, patients with immune-compromised conditions may have a higher risk of progressing to the severe hyperinflammation phase leading to death.

Moreover, the lung parenchymal injury is mediated by inflammatory responses with vasodilation, endothelial permeability, and leukocyte recruitment (Fig. 1). The features

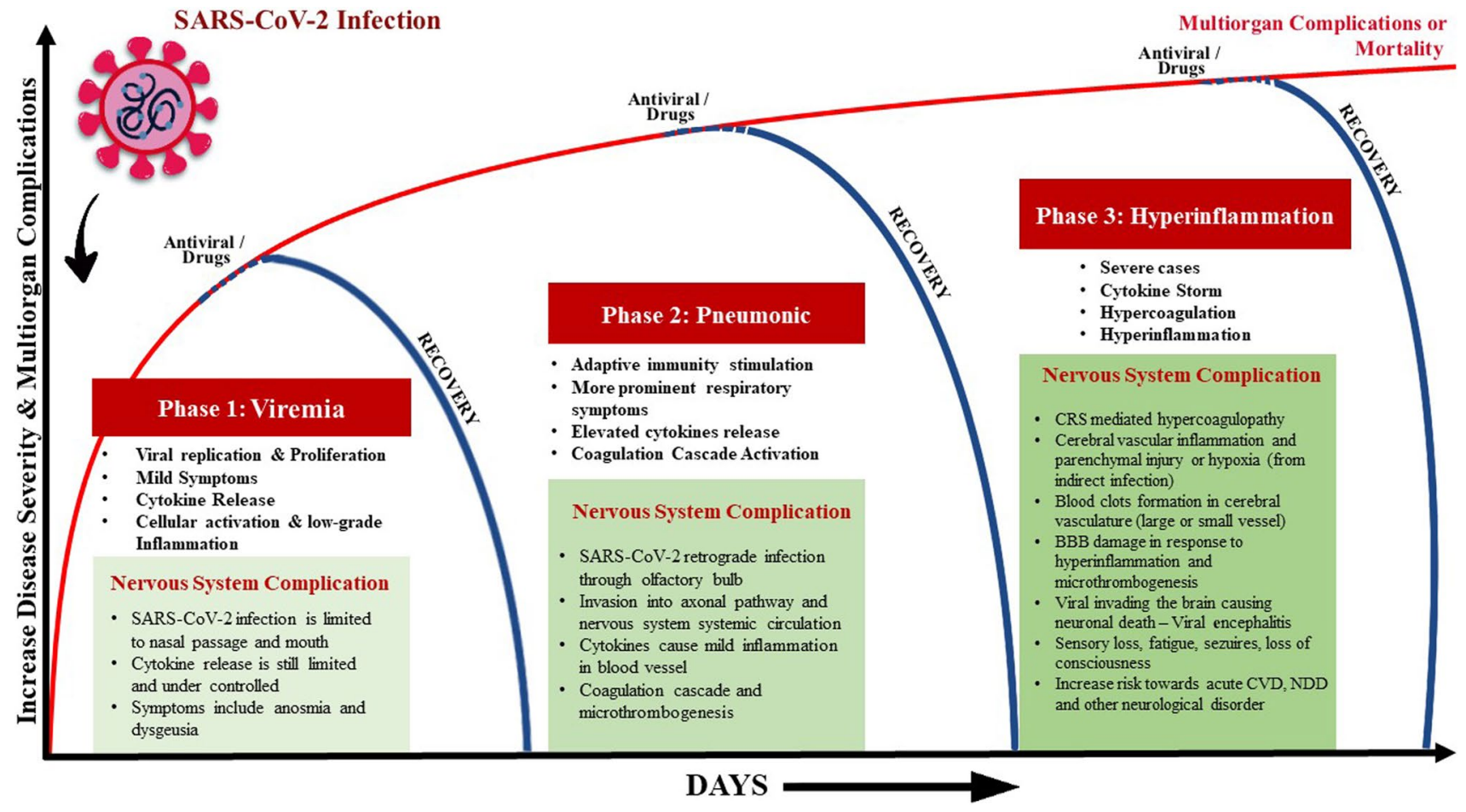

Fig. 2 The known phases of COVID-19 infection: from viremia, pulmonary to multi-system manifestations; emphasis made on the impacts on the nervous system. Also shown are the simplified underlying COVID-19 likely pathomechanisms as the infection progresses, and the current corresponding therapeutic targets in the clinical man- agement of each phase. It is probable that even after the recovery at any phase of the disease, the involvement of cellular activation byproduct (such as microparticles) may persist and result in an undesirable health sequel 
of respiratory dysfunction in this phase are distinct from the typical ARDS. The pulmonary compliance is slightly decreased in intubated COVID-19 patients [41] and responsive to prone positioning and moderate levels of positive end expiratory pressure oxygen therapy. Unlike typical ARDS where alveoli are primarily affected [42], combination of severe hypoxemia without significant reduction in pulmonary compliance is rare. However, in COVID-19, it disrupts the pulmonary vascular endothelium resulting in a diffuse systemic disease. This is aggravated by a rapid activation of the coagulation cascade, which leads to pervasive micro- and macro-thrombogenesis within the lungs and other organs. Evidently, a markedly raised D-dimer level has been associated with a worse prognosis. Pulmonary vascular occlusion caused by the thrombotic microangiopathy and/ or pulmonary embolism leads to accumulation of respiratory dead space. Hence, this inflicts further damage to the lung whereby some patients could progress into ARDS-like features $[41,42]$. Thus, multiple pathomechanisms are being implicated in the progression to ARDS in COVID-19 that feature disproportionate endothelial damage with hypoxic pulmonary vasoconstriction (i.e., ventilation-perfusion mismatch), hypoxemia, as well as thrombogenesis [43]. In some cases, these occur within the background of heightened inflammatory responses that progress into the next phase of the infection.

\section{COVID-19 Complications}

It is recognized that even with reducing viral loads, some COVID-19 patients continue to mount heightened inflammatory storms leading into the final, hyperinflammation phase of the disease. This phase features systemic inflammation and distant organ damage that cause multi-organ dysfunction syndrome (MODS) [39, 44] (Fig. 2). Several serum markers found to be elevated and may influence prognosis include C-reactive protein (CRP), pro-inflammatory cytokines such as interleukin (IL)-2, IL-6, IL-7, interferon- $\gamma$ inducible protein 10 (IP-10), granulocyte-colony stimulating factor (G-CSF), tumor necrosis factor alpha (TNF- $\alpha$ ), macrophage inflammatory protein 1 alpha (MIP-1 $\alpha$ ), and monocyte chemoattractant protein 1 (MCP-1) [45-48].

Hence, these pathophysiological mechanisms lead to both focal and systemic microvascular inflammation, which in turn trigger endothelial activation and aggravate the prothrombotic states (Fig. 2). The massively elevated serum D-dimer levels may also be due to the vascular disease reported in this phase. Clinically, a significant number of hospitalized COVID-19 patients also suffered from acute pulmonary vascular thrombosis or embolism, myocardial infarction, CVD, and systemic arterial thrombosis that worsened their prognosis [7]. There are amplified fibrin degradation products (FDPs) reported in most severe cases with
ARDS, septic shock, concurrent bacterial infections, disseminated intravascular coagulopathy (DIC), and MODS $[45,49]$. In such cases, heparin has been used as part of the multi-therapy regime. Thus, given this immune-coagulation systems interaction, heparin inhibition of thrombin activity may attenuate the inflammatory storms [50]. Similarly, potentials of corticosteroids, tocilizumab, sarilumab, and monoclonal antibodies against IL-6 receptor are actively being pursued to mitigate the severity of this phase.

\section{COVID-19 and Cerebrovascular Disease}

It is well known that viral infections can inflict severe damage to the structure and function of the nervous system, for example, viral infection in central nervous system (CNS) causing encephalitis and acute demyelinating lesions while systemic viral infections causing toxic encephalopathy [51]. Numerous evidence and case series reported SARSCoV-2 complications are not limited to respiratory system but include obvious manifestations of neurological disturbances including seizures, anosmia, stroke, encephalopathy, confusion, acute CVD, and total paralysis [9, 52-54]. It is estimated about $20 \%$ of COVID-19 patients admitted to the intensive care unit (ICU) exhibited neurological consequences with a higher risk of mortality [55, 56]. Given the wide-ranging healthcare accessibility to COVID-19 patients management worldwide, these neurological symptoms may manifest until after discharge from COVID-19 hospitalization, and some may even result in death [57]. Alarmingly, recovered COVID-19 patients are believed to be at a possible higher risk for long-term effects of neurodegenerative, neurocognitive, and neuropsychiatric disorders such as dementia, depression, anxiety, AD, and Parkinson's disease [58, 59] (Fig. 2).

Furthermore, gradual reports have emerged since the outbreak of COVID-19 demonstrating the link between COVID-19 and CVD/acute CVD among those with a higher risk of cardio-embolic as well as arterio-arterial embolic events $[54,57,60,61]$. Through neuroimaging, $\mathrm{Li}$ et al. [62] confirmed the evidence of CVD and reported that most COVID-19 patients had cerebral ischemic infarcts in both large and small arterial vessels [62]. This is in parallel with the observed complication of DIC which is higher among COVID-19 patients with higher FDPs levels and prolonged prothrombin time (PT) and activated partial thromboplastin time (aPTT) [57, 62], with risk of death. In Wuhan, where the disease originated, about $36 \%$ of patients with COVID-19 showed signs and symptoms of acute CVD, where up to $6 \%$ among those with a more severe disease (elevated D-dimer and depleted platelets) [9, 63, 64]. The common types of acute CVD associated with COVID-19 infection in most reports are cryptogenic strokes (65\%) [60]. 
Nevertheless, the causality between CVD and COVID-19 infection remains obscure, although recognized multi-factorial triggers include hypercoagulability, hyperviscosity, thrombogenesis, and cytokines release syndrome (CRS) as observed in growing case series [46, 57, 63] (Fig. 1).

\section{Cerebral Small Vessel Disease}

Accumulating body of evidence implicates SARS-CoV-2 role in eliciting the systemic event (i.e., inflammation and pro-coagulant/thrombotic cascade) within the large vessel environment linking COVID-19 with large vessel strokes. Hence, similar repercussion may well extend into the small vessel microenvironment within the brain [65]. Since the involvement of small vessel disease (SVD) has been confirmed as a complication from COVID-19 infection, it is important to appreciate that one of the most significant manifestations of SVD (i.e., stroke) occurs from the occlusion (ischemia) of small blood vessels deep within the brain or so-called cerebral ischemia or ischemic stroke [66]. Prevalent among healthy aging adults, about $30 \%$ of ischemic or lacunar strokes are thought to represent CSVD [66]. CSVD is due to the spectrum of complex and overlapping pathophysiological mechanism and often occult or asymptomatic in nature that often incidentally found after neuroimaging (i.e., magnetic resonance imaging, MRI). However, it is well supported that CSVD is mainly due to the pathological consequences of SVD on the brain parenchyma rather than the underlying diseases of the vessels [67]. Therefore, the term CSVD signifies a brain parenchyma injury (often progressive or accumulating) associated with distal leptomeningeal and intracerebral vessel pathology that resides in poorly collateralized subcortical gray and deep white matter. Moreover, it is mainly due to several focal or diffuse microvascular pathological processes that affect and cause occlusion to the small perforating cerebral capillaries (of sizes 50-400 mm), small arteries (mostly branches of MCAs), arterioles (diameter $<0.1 \mathrm{~mm}$ ), and venules that penetrate and supply the brain cortical and subcortical region [68, 69].

There are several etiopathogenic classifications of CSVD. However, the most well-recognized forms of CSVD are the amyloidal CSVD (e.g., sporadic, and hereditary cerebral amyloid angiopathy [CAA]) and non-amyloidal CSVD including age-related and vascular risk factor-related SVD (i.e., arteriolosclerosis and age) [68]. Other less common forms of CSVD include inherited or genetic (monogenic) CSVD that is recognizably different from CAA (i.e., Fabry's disease and cerebral autosomal dominant arteriopathy with subcortical ischemic strokes and leukoencephalopathy [CADASIL]), inflammatory and immunologically mediated CSVD, venous collagenosis, and other CSVD (i.e., non-amyloid micro-vessel degeneration in AD and post-radiation angiopathy) [70]. Several manifestations of
CSVD can be seen through clinical, such as acute lacunar infarct and intraparenchymal hemorrhage, and radiological (i.e., neuroimaging), such as white matter hyperintensities (WMHs) of presumed vascular origin, cerebral microbleeds (CMBs), cortical microinfarcts, lacunar infarcts and recent subcortical brain infarcts (RSBI) and enlarged perivascular spaces (PVS), or pathological phenomena with multifaceted etiologies [13, 69, 71]. However, the lack of standardization and consistency in neuroimaging techniques lead to the development of STandards for Reporting Vascular changes on nEuroimaging (STRIVE), aided in the imaging based visual identification and classification of CSVD spectrum [72]. Figure 3 describes the neuroimaging correlates of different CSVD manifestations based on the STRIVE method and COVID-19 findings.

\section{COVID-19 and CSVD: Inter-current Risk Factors}

A recent study has highlighted that young and healthy individuals either symptomatic (i.e., cough or fever) or asymptomatic of COVID-19 can present with large vessel stroke [76], while hypertensive COVID-19 patients are more likely to develop CVD, both large and small vessel strokes [77]. Moreover, metabolic syndromes such as obesity and high body mass index (BMI) have been associated with the severity of respiratory viral infection [78] and COVID-19, hence being considered a risk factor for acquiring the infection $[79,80]$. However, there are several and complex known risk factors towards development and progression of CSVD manifestation. For example, increase in WMHs, lacunar infarcts, and recent subcortical brain infarct (RSBI) were associated with lifetime exposure towards cardio-cerebrovascular risks such as metabolic syndrome (i.e., hypertension, obesity, hyperlipidemia, dyslipidemia), lifestyle (i.e., smoking, extreme alcohol intake), and T2DM which can progress towards acute ischemic (lacunar) stroke [81]. Apparently, age has served as one of the most significant determinants of the onset, proportion, and progression of all CSVD manifestation (prevalent with healthy aging $[\sim 6 \%]$ in CMBs). A higher risk of CMBs has been found in individuals with symptomatic CVD such as ischemic stroke and intraparenchymal hemorrhage [11]. Therefore, metabolic syndromes and age are major risk factors for CVD-related COVID-19 infection.

Meanwhile, genetic factors such as $\mathrm{NOTCH} 3$ gene (chromosome 19) mutation as seen in CADASIL; mitochondria DNA mutation as seen in mitochondrial encephalomyopathy; lactic acidosis; and stroke like syndrome (MELAS), Fabry's disease, and familial CAA increase the burden and prevalence of CSVD [82]. One case report demonstrated the presence of chronic SVD in a young (38 years old) COVID19 patient with a family history of CADASIL, whereby bilateral acute cerebral infarcts in multiple locations within 


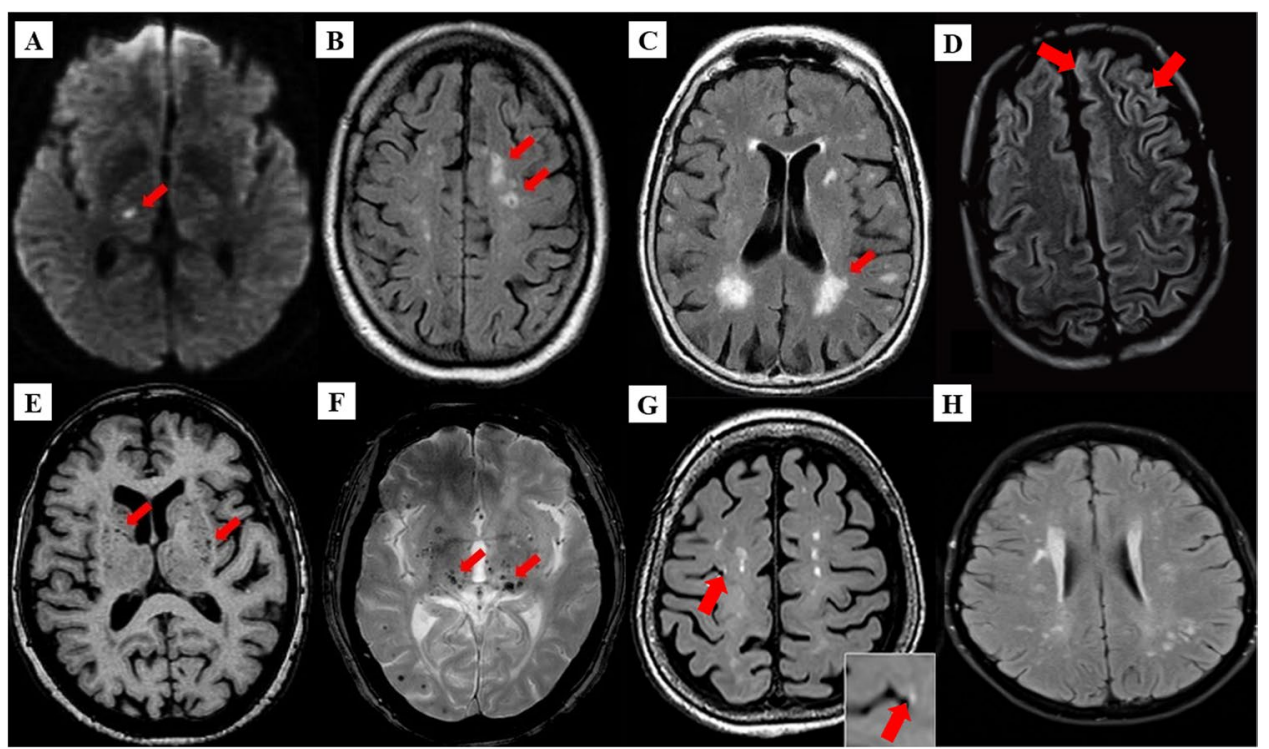

Fig. 3 Neuroimaging correlates of CSVD based on STRIVE method. A Recent small subcortical infarct (RSBI) on diffusion weighted imaging (DWI) (red arrow). Usual diameter is around 3-15 mm, with hyperintense rim surrounding ovoid cavity. RSBI seen as increased T2-weighted, fluid attenuated inverse recovery (FLAIR), and DWI signal intensities and decreased T1-weighted signal and iso-intense in $\mathrm{T} 2 *$-weighted gradient recoiled echo (GRE) signal and susceptibility weighted imaging (SWI). RSBI is best identified through DWI with usual infarct diameter of $\leq 20 \mathrm{~mm}$. B Lacunar infracts on FLAIR (red arrow). Lacunar infarcts appeared as increase hyperintensity in T2-weighted signal, decrease T1-weighted, and FLAIR signal and iso-intense in DWI. Usual diameter is around 3-15 mm, with hyperintense rim surrounding ovoid cavity. $\mathbf{C}$ White matter hyperintensities (WMHs) of presumed vascular origin on FLAIR (arrow). WMHS seen as increase intensity or hyperintensity on T2-weighted imaging, T2*-weighted GRE and FLAIR (best identified); iso-intense on DWI; and hypointense (decrease intensity) on T1-weighted imaging. D FLAIR WMHs at left superior frontal gyrus and left anterior cingulate cortex, from a 60-year-old COVID-19 patient without history

internal border zone (or subcortical lesion) distribution (i.e., at the junction of two arterial territories) were found after neuroimaging. Hence, this suggests the involvement of small vessel attributable to compromised cerebral microcirculation [75] (Fig. 3).

Intriguingly, a recent retrospective case-control study (41 COVID-19 cases) had shown that COVID-19 was an independent risk factor for cerebral ischemia (i.e., acute ischemic stroke), whereby the association was achieved even after age, sex, and other risk factors (i.e., hypertension, T2DM) were adjusted and matched [83], suggesting that age is not associated with COVID-19-mediated CVD. This is supported by Moriguchi and colleagues [84] who reported hyperintense signal on brain MRI in the hippocampus and inferior horn of the right ventricle and right mesial temporal lobe in a young (24-year-old) COVID-19 patient [84] that indicated the presence of CSVD manifestation. Additionally, a case report highlighted the involvement of cerebral of seizures. E Enlarged perivascular spaces (PVS) on T1-weighted imaging (red arrow) with usual diameter of $\leq 2 \mathrm{~mm}$. PVS is seen as decrease FLAIR and T1-weighted signal intensity, with increase T2-weighted signal. Meanwhile, T2*-weighted GRE and DWI appeared iso-intense, and they also appeared in similar signal intensity with cerebrospinal fluid (CSF). F Cerebral microbleeds (CMBs) on T2*-GRE (red arrow). CMBs are small, rounded areas of signal void with blooming, whereby they were visualized as iso-intense T1- and T2-weighted signal, FLAIR, and DWI. They are best identified under T2*-weighted GRE or SWI as reduced signal intensities. Usual diameter is around $\leq 10 \mathrm{~mm}$ (mostly $2-5 \mathrm{~mm}$ ). G 3 Tesla-MRI representation of cortical microinfarcts (red arrow) on T1-weighted (hypointense). H FLAIR WMHs in multiple foci, including the deep white matter, periventricular, and subcortical regions in COVID19 patient with CADASIL. Notes: $(\mathbf{A}),(\mathbf{B}),(\mathbf{C}),(\mathbf{E})$, and $(\mathbf{F})$ were adapted from Mustapha et al. [70]; (D) was adapted from Muhammedi et al. [73]; (G) was adapted from Takasugi et al. [74], and (H) was adapted from Williams et al. [75]

microcirculation insults with a COVID-19 test positive but asymptomatic young individual (i.e. without COVID-19 flu-like symptoms) who suffered from a sudden onset dysphasia and left hemiparesis where subsequent neuroimaging revealed two recent small infarctions in the right perirolandic cortex (hence, involving small vessel) without signs of any previous ischemic/hemorrhagic lesion and with rigorous exclusions of other conventional stroke risk factors [85]. Thus, the involvement of symptomatic small vessel stroke is recognized in COVID-19 small case series and often regarded as cryptogenic [57,63].

Additionally, Hanafi and colleagues [86] had reported the possibility of a small intracranial vascular injury in the distribution of cerebral distal perforating arteries (i.e., enlarged PVS, deep WMHs) without large vessel (intra- or extracranial) involvement as COVID-19 neurovascular complications in an older individual suggestive of small vessel damage [86], while Brun and colleagues [87] reported the 
involvement of acute demyelination (restricted diffusion with FLAIR-MRI hyperintensities) as seen from bilateral and asymmetrical periventricular (involving corpus callosum) and deep WMHs of a 54-year-old COVID-19 patient, hence suggesting cerebral ischemia due to small vessel vasculitis [87]. Meanwhile, a prospective study conducted on 60 recovered COVID-19 patients (age- and sex-matched) found more than half $(55 \%)$ presented with neurological syndromes [88]. Neuroimaging study (including diffusion tensor imaging, DTI) revealed that these individuals had bilateral enlargement of gray matter volumes (GMV) in their central olfactory system, suggesting that SARS-CoV-2 may invade CNS through olfactory bulb via retrograde route and the GMV enlargement indicates neuronal compensation during recovery period after COVID-19 [88]. Besides, DTI parameters revealed that these individuals had higher mean diffusivity (MD) and lower fractional anisotropy (FA) in white matter tracts (i.e., corona radiata, external capsule, and superior fronto-occipital fasciculus) [88], suggesting an increase in white matter fibers alignment and limited diffusion prior to an intrinsic neuronal remyelination after an infection or during the recovery period [89]. Collectively, there is enough evidence to deduce the likely cerebral microcirculation (structural and function) disruption and cerebral white matter loss of integrity during and after (i.e., recovery period) COVID-19 infection, hence indicating the risk and consequences of COVID-19 on onset and progression of CSVD even after the infection has ceased, be it asymptomatic or symptomatic manifestations.

\section{COVID-19 and CSVD: Putative Pathomechanisms}

Relatively small micro-vessels play essential roles in CNS in terms of neurovascular unit or the blood-brain barrier (BBB). To date, various and intensive investigations have been carried out to study the mechanism of interaction between cerebral parenchyma and its surrounding microvasculature [90]. However, it is well accepted that neurovascular unit or BBB owns the prior role in brain health and plasticity (capacity to recover) from insults that may initiate the pathologic cascade towards neurodegenerative disease (NDD). Two classical clinicopathologic representations of CSVD are linked to arteriolosclerosis or lipohyalinosis (thickening and/or damage the wall of arterioles) and occlusion of cerebral penetrating arteries [91]. However, most of the SVD are representation of cerebral arterial microcirculation flow obstruction (intrinsic or extrinsic). For example, an arteriolar occlusion or narrowing resulted in ischemia as seen in small lacunar infarcts.

Various pathological changes of CSVD not only give rise to cerebral parenchyma damage (i.e., axonal injury, neuronal apoptosis, demyelination, and oligodendrocyte damage), with consequent neurological symptoms, signs, and multifaceted neuroimaging findings [92]. Nonetheless, the underlying pathomechanism of CSVD remains contentious despite the growing insights from histopathological, epidemiological, and physiological studies. Several systemic dysregulations including abnormal coagulation, elevated microthrombosis, genetic mutation, increase cellular activation, inflammation, and oxidative stress are the major contributors towards endothelial dysfunction, altered cerebral blood flow $(\mathrm{CBF})$, and $\mathrm{BBB}$ breakdown which provide further insights on the current known pathomechanism of CSVD.

Moreover, during the course of COVID-19 infection, the hypercoagulability and thrombotic vascular events are known to be associated with neurovascular involvement such as acute CVD [52]. Interestingly, SARS-CoV-2 has been detected in the cerebrospinal fluid (CSF) indicating its direct ability to invade and infect the nervous system from ACE2 receptor-mediated entry through retrograde route [52]. Hence, various studies have proposed several plausible mechanisms of COVID-19-related nervous system damage including direct infection injury such as viral neurotropism through neuronal pathway (retrograde route) and systemic blood circulation or hematogenous route (i.e., endothelial dysfunction, coagulopathy, inflammation). Other indirect infection also has been proposed such as cardio-embolism and viral proliferation in the lung that mediate hypoxia injury and immune injury $[52,93]$. These proposed mechanisms are associated with the current spectrum of dynamic cerebral microvascular pathological process towards the onset and progression of CSVD. Hence, the foregoing sections will deliberate on the potential pathomechanism of COVID-19-related CSVD.

\section{COVID-19 Neurotropism: Neuronal Pathway}

Researchers have reported the presence of viral genetic materials and proteins from the samples of nervous tissues such as CSF or brain tissues, suggesting neurotrophic properties of viruses whereby they can directly invade the nervous tissues that trigger subsequent immune responses from nerve cells such as microglia, macrophages, or astrocytes and cause nervous system injury [94-96]. After the invasion into the neural tissues, the viruses can migrate and further infect the sensory or motor neurons, hence achieving anterograde or retrograde transport aided by motor proteins (i.e., kinesins and/or dynein) [97]. In this case, olfactory neuronal transport is the main example. Evidently, in COVID-19 early viremia phase, many patients have reported anosmia and dysgeusia, probably from the spread through the olfactory epithelium or cribriform bone in the nasal cavity and reach the brain through retrograde route transfer, thought to occur within seven days after infection in the respiratory 
tract [98]. A recent study had confirmed through genomic sequencing that new pneumonic virus such as SARS-CoV-2 were present in CSF, neural, and cerebral capillary ECs of COVID-19 patients, supporting the fact that SARS-CoV-2 can infect the CNS from peripheral neuronal pathway and mediate further nervous system damage [99, 100]. Interestingly, one pre-clinical animal study had shown that the removal of the olfactory bulb from mice inhibited the direct invasion of SARS-CoV infection into the CNS [101].

Furthermore, in the pneumonic phase of the infection, the presence of ACE2 receptors in glial cells in the brain and neurons in the spinal cord provide access to the virus proliferation [97]. In this case, SARS-CoV-2 spike protein interaction with ACE2 receptors invades the capillary endothelium, hence breaching the BBB to infiltrate the nervous system $[61,63]$, and increases the risk towards CSVD and other neurovascular disease. The involvement of the renin-angiotensin system (RAS) also leads to an exaggerated blood pressure increment that poses a risk of acute cerebral hemorrhage [63, 64]. In the final, hyperinflammatory phase, the presence of CRS with further deterioration in the neurological status of COVID-19 patients may result in altered sensorium, seizures, or even death [64]. Furthermore, neurotropic nature of the virus could also activate glial cells and induce a pro-inflammatory state that correspond with the elevated serum levels of inflammatory markers such as IL-6, IL-12, IL-15, and TNF- $\alpha$ [64].

Apart from direct infection through neuronal pathway, another recent report had shown SARS-CoV-2 direct infiltration through hematogenous route of cerebral small vessel-ECs, causing endothelial inflammation and dysfunction or endotheliitis [87]. Subsequently, such endotheliitis would lead to cerebral vasoconstriction, BBB damage, and cerebral vasculitis and likely to pose imminent cerebral ischemic damage (given the proximity to deep and periventricular white matter) despite an apparent absence of overt neurological symptoms $[43,87]$. Thus, little is known at present on the likely impact of such COVID-19-related disease mechanisms or complications on the brain small vessel microenvironment, especially on the recognized asymptomatic manifestation of CVSD. Therefore, the foregoing sections will elaborate on the COVID-19-mediated direct complications that may contribute to the pathomechanism of CSVD through several processes including cytokine stormmediated hyperinflammation, oxidative stress, coagulopathy, cellular activation, and microthrombosis.

\section{Cytokine Storm and Oxidative Stress}

SARS-CoV-2 infection in COVID-19 patients has been widely reported to induce cytokine storm or CRS, whereby a burst of cytokines release triggers the hyperinflammation and immune cells infiltration in their lungs [102, 103]
(Fig. 1). Such a phenomenon may also be the factors of onset for acute CVD [46, 49]. However, during the early stage of the infection (i.e., viremia) upon entering the nervous system, the SARS-CoV-2 binding to the ACE2 receptor is only limited to the gustatory and nasal epithelial cells. The activated CRS is still minimal at this stage, whereby patients may often recover after having only taste and smell impairments [104] (Fig. 2). However, past reports of SARS$\mathrm{CoV}$ and MERS-CoV patients have demonstrated extensive CRS as the infection progresses, particularly in severely ill patients [105]. Moreover, pre-clinical animal study had shown that these viruses were able to aggravate the cerebral ischemic injury by triggering the cytokine cascade and potentiate the risk towards cerebral hemorrhage after administration of tissue plasminogen activator (tPA) [106]. Therefore, CRS seems to elevate the vascular permeability, edema, and widespread inflammation, and followed by MODS [107].

In COVID-19 patients, increased plasma pro-inflammatory cytokines such as IL-1, IL-6, IL-8, and TNF- $\alpha$ levels have been reported that may contribute to CRS onset in severe COVID-19 patients [102, 103]. IL-1 is produced by activated macrophages and dendritic cells in response to microbial stimuli that triggers fever, systemic inflammation, and tissues destruction. IL-1 is thought to exacerbate CRS, and phase 3 randomized control trial (RCT) of sepsis patients showed that IL-1 receptor antagonist anakinra (already approved for the treatment of rheumatoid arthritis) demonstrated survival benefits for patients with hyperinflammation [46, 108]. In severe COVID-19, the expression of IL- $1 \alpha$, IL- $1 \beta$, and IL- 1 receptor and their associated downstream signaling molecules were induced before respiratory function worsened. T cells activation was also observed, suggesting that IL-1 pathway exacerbated the disease through T cell-mediated cytotoxicity [109]. A retrospective study of severe COVID-19 patients with acute severe respiratory failure and systemic inflammation showed that those treated with anakinra demonstrated clinical improvements without deaths, decrease in oxygen requirements, and prolonged ventilation-free days [110]. Moreover, in severe COVID-19 patients, hyperinflammatory response has been reported in relation to ARDS and MODS [111]. In an independent retrospective cohort study of COVID-19 patients with moderateto-severe ARDS and hyperinflammation, anakinra administration significantly improved the survival compared with patients receiving standard treatment [110]. Validation of anakinra as an anti-inflammatory treatment for COVID-19 is currently underway in RCTs (e.g., NCT04324021).

Numerous reports have also proposed IL-6 as an important mediator of CRS and severe respiratory failure $[112,113]$. In acute inflammation, IL-6 is produced by activated macrophages and neutrophils [105, 114]. IL-6 promotes inflammatory cell infiltrate by rescuing $\mathrm{T}$ cells 
from apoptosis, promoting the maturation of $\mathrm{T}$ cells into effector T cells and inducing vessel permeability [114, 115], potentially contributing to organ damage by hyperinflammation and T cell-mediated cytotoxicity. Post mortem analyses of COVID-19 patients with ARDS complications showed hyperactivated cytotoxic $\mathrm{T}$ cells with concentrated cytotoxic granules [7]. A recent meta-analysis reported that mean IL- 6 concentrations raised to nearly threefold higher in complicated versus uncomplicated COVID-19 patients and 9 out of 10 studies examined showed elevated IL-6 levels associated with worse prognosis [116].

Furthermore, observational and retrospective studies in COVID-19 patients have suggested the clinical efficacy of IL-6 blockade with therapeutic antibodies including tocilizumab [117], sarilumab, and siltuximab [118]. As such, RCTs are being conducted to examine the efficacy of IL- 6 blockade in COVID-19 patients. In a press release on 29 July 2020, it was reported that the phase III COVACTA study (NCT04320615) involving 450 COVID-19 patients with severe pneumonia failed to meet its primary endpoint where tocilizumab administration did not confer improved clinical status compared with placebo. Nonetheless, tocilizumab-treated patients showed better trends in the duration of hospital stay and ventilator-free days. Moreover, COVACTA's broad patient selection criteria and without apparently stratifying patients based on symptoms of hyperinflammation may have masked the potential benefits of tocilizumab [119], and the full trial data are eagerly awaited. The efficacy of tocilizumab is also being assessed in the RECOVERY late stage RCT of tocilizumab versus standard of care (NCT04381936) in over 850 COVID-19 patients.

It has been established that systemic inflammation confers debilitating effects on the brain, and the likely impact on the pathophysiology of CVD. Systemic inflammation induced by conserved pathogen-associated molecular patterns such as lipopolysaccharide and double stranded RNA in concert with pro-inflammatory cytokines could trigger inflammatory response from endothelium (i.e., endotheliitis) and cellular activation for a wider CNS inflammation [120]. Systemic TNF- $\alpha$ increase could induce the levels of IL- $1 \beta$ in the blood and brain, and that hypothermia and locomotor activity can be induced by IL-1 $\beta$ and IL-6 [121]. Recently, it has been shown that systemic inflammation is associated with CSVD. The severity and progression of CSVD are strongly associated with systemic inflammation characterized by increased circulating IL-6 and its production by monocytes [122]. Furthermore, higher serum levels of IL- $1 \alpha$ and IL- 6 were significantly associated with the primary outcomes of CSVD in both univariable and multivariable analysis adjusted for age, sex, and CSVD radiological markers, and both ILs levels had the strongest association with recurrent stroke in the disease [123].
In COVID-19 patients, the prolonged exposure to physiological stress and hyperinflammation during CRS may contribute to various neurological symptoms (i.e., neurocognitive, and neuropsychiatric) [124]. Hence, alongside the systemic inflammation is heightened oxidative stress, and both responses have been associated with the pathogenesis of CSVD as in arteriosclerosis [125]. Oxidative stress-related species such as reactive oxygen species (ROS) and reactive nitrogen species (RNS) contributed to cerebral vascular oxidative stress by elevating the inflammatory response that influence the progression of clots or thrombus, increase proinflammatory cytokines (i.e., IL-6, IL- 8 , TNF- $\alpha$, monocytes chemoattractant proteins-1 [MCP-1]), endothelial function, and increased expression of vascular endothelial adhesion molecules (VCAM-1) and intracellular adhesion molecules (ICAM-1) [126]. Subsequently, elevated levels of RNS and ROS have been associated with oxidative stress-mediated cell migration and proliferation, DNA damage, necrosis and apoptosis, cellular autophagy, endothelial dysfunction, and endoplasmic reticulum stress [127]. Furthermore, following overproduction of pro-inflammatory cytokines is the activation of transcription factors (i.e., nuclear factor kappa $\mathrm{B}$ [NF- $\kappa \beta]$ and/or nuclear factor (erythroid-derived 2)-like 2 [Nrf2]) and signal transduction cascades [128] that elevate the release of cytokines and chemokines that further enhance inflammation [129]. However, nitric oxide (NO) release by ECs inhibits the expression of NF- $\kappa \beta$ and adhesion molecules; hence, NO serves as a crucial anti-inflammatory factor and important for vascular vasodilation. However, this ability is diminished following ECs damage with the systemic inflammation [130].

Additionally, ROS may act on the ECs-induced inflammation through the disruption of inter-endothelial junction, gap formation, actomyosin contraction, and altered phosphorylation or expression of junctional adhesion molecules [131, 132], leading to endotheliitis. Therefore, COVID-19 endotheliitis has been proposed to cause compromised microvascular structure and function in various vascular beds, resulting in the clinical sequelae in COVID19 patients [43]. Moreover, the released cytokines from the induced inflammation of ECs through extracellular matrix (ECM) degradation is followed by BBB breakdown [133]. Besides endothelium, there exists crosstalk among cellular components of the BBB such as pericytes, astrocytes, and oligodendrocyte precursor cells (OPCs) that are likely to be involved in the microvascular damage as precursors for the onset and progression of CSVD [134, 135]. In fact, mice infected with coronavirus had developed acute demyelination with the involvement of microglia, ECs, and astrocytes [136]. In relation to this, reduced white matter integrity due to changes in oligodendrocytes has been shown in CSVD, whereby the ECs-OPC signaling was compromised that altered the ECs' ability to secrete the releasing factor 
crucial for the growth and survival of OPCs, which in turn caused oligodendrocytes damage [137]. An increased BBB damage and permeability further induced the degradation of basement membrane of ECs and accumulation of ECM components leading to stiffening of vessel walls [138]. Furthermore, the BBB damage will further intensify as the deposition of blood components such as platelets, microparticles, and fibrin increased after BBB breakdown. Several studies supported that changes in walls of small vessels in the brain due to BBB breakdown would lead to ischemic events classified as WMHs, lacunar infarcts, and CMBs, with and without COVID-19 infections [87, 139-141].

In addition, obesity as part of the metabolic syndrome is thought to elicit low-grade inflammation in relation to ARDS [142] and is associated with an elevated cytokine IL-33 level that mediated the stimulation of pro-coagulant tissue factor (TF) release by ECs [143]. Hence, in relation to COVID-19, these factors increased the likelihood of obese patients to develop a more severe COVID-19 while at risk of stroke [144]. Collectively, these data indicate that proinflammatory cytokines and oxidative stress are involved in the pathogenesis and severity of CSVD. As CRS is one of the hallmarks of critically ill COVID-19 patients, it is plausible that administration of immune-suppressive medications such as IL-1 or IL-6 blockade with therapeutic antibodies and antioxidative agents may also mitigate the risk of CSVD in COVID-19 patients.

\section{Hypercoagulation and Cerebral Microthrombosis}

In the later stage of COVID-19 infection (i.e., pneumonic and/or hyperinflammatory stage), SARS-CoV-2 is reported to further heighten the activation of uncontrolled cytokines release leading to hyperinflammation, elevation of CRP, ferritin, and D-dimer levels [104] (Fig. 2). Systemic proinflammatory factors such as ILs, TNF- $\alpha$, and CRP are responsible for the primary molecular events elicited by abnormal coagulation or hypercoagulable state $[104,145$, 146], and SARS-CoV-2 is thought to foster a pro-inflammatory microenvironment and induce prothrombotic state leading to thrombogenesis, formation of blood clots, and small or large vessel occlusion [76, 147]. Besides, the elevated immune response may also lead to vasculitis in nerves and muscles, alongside with immune-mediated peripheral, cranial nerves and/or muscle injury [104].

In general, the coagulation process or pathway serves to maintain hemostasis or to control bleeding, promote healing, and prevent spontaneous bleed [148]. The coagulation pathway is controlled by certain naturally occurring inhibitory elements or anticoagulants such as protein S, protein $\mathrm{C}$, antithrombin, and tissue factor pathway inhibitor (TFPI) that control and limit the formation of clot to prevent propagation of thrombus/microthrombus or further thrombosis/ microthrombosis [148]. Altered pro-coagulant properties of such coagulation factors would stir imbalance in the pathway, either with increased or decreased activities of a given factor [149]. Generally, the thrombogenic elements of coagulation factors are produced from two sites: the vessel wall (i.e., TF, exposed endothelium, and collagen) and the circulating elements (i.e., platelets, platelet activating factor, prothrombin [factor II], fibrinogen [factor I], von Willebrand factor [vWF], and numerous clotting factors). Certain events such as physiological disturbance, blood abnormalities, infection, elevated pro-inflammatory cytokines activities, and disturbance in the primary hemostasis (i.e., platelet plug formation at the insulted site of exposed ECs of the vessel wall) would result in the imbalance of the coagulation system, hence termed as coagulopathy $[150,151]$. Thus, in relation to COVID-19 infections, an altered systemic coagulation cascade in microcirculation can be activated at early disease process, and platelet activations are the main player in microthrombi/clots formation and its plausible impact on the pathomechanism of CSVD (Fig. 1).

COVID-19-associated coagulopathy reported among COVID-19 patients warrant further investigation as SARSCoV-2 has no known direct intrinsic pro-coagulant effect [152]. Moreover, emerging evidence has shown that SARSCoV-2 can cause microvascular, arterial, and venous thrombosis through ACE2 receptor on the ECs and smooth muscle cells (SMCs) hence potentiate organ injury [153]. In addition, SARS-CoV-2 may also invade ECs of the cerebral arterioles eliciting direct and/or immune-mediated injury without compromising systemic response and hence partly explains why COVID-19 patients with no systemic symptoms are at risk of cerebral vascular injury and cryptogenic stroke [85]. In addition, hypercoagulability in COVID-19 patients has been reported to be associated with elevated acute-phase reactant levels including CRP and fibrinogen, thus being used as biomarkers with prognostic values [154, 155]. Abnormalities in coagulation system are frequent among fatal cases of COVID-19 including shortened aPTT and prolonged PT in coagulation cascade [64, 156]. Moreover, FDPs such as D-dimer and other FDPs are the most widely used and direct prognostic biomarkers for COVID19 severity and often in fatal cases compared to non-severe patients with a higher plasma D-dimer [45, 155, 157-159] and, thus, posed an increased risk towards CSVD-associated microthrombosis [93].

As elaborated previously, the viral infection may potentiate the innate immune response such as systemic inflammatory activation. The response can activate the coagulation cascade followed by the generation of thrombin or generally referred as thrombo-inflammation or immuno-thrombosis as part of crucial communication components among cellular and humoral amplification pathways [160, 161]. Furthermore, infection-based inflammatory response mediates 
coagulation cascade through multiple pro-coagulant pathways. In this case, virus-derived polyphosphates may induce the activation of platelets and factor XII in coagulation pathway, thus amplifying the downstream pro-coagulant response especially the intrinsic pathway of coagulation cascade [162]. Additionally, elevated levels of viral infection-based inflammatory biomarkers such as pro-inflammatory cytokines instigate the activation of vascular ECs and endothelial injury/dysfunction that further promote the thrombo-inflammation [163]. Another important component that activates and enhances the contact and prothrombotic pathway respectively is the cell-free DNA and histones neutrophil extracellular traps (NETs) that present and propagate as part of the intravascular thrombi, hence triggering the generation of thrombin $[163,164]$.

SARS-CoV-2 infection also can directly cause cellular activation (e.g., ECs, neutrophils, monocytes, macrophages, $\mathrm{T}$ cells) that provoke further pro-inflammatory cytokines release and hence increase the disruption of endothelial function and integrity, followed by the release of vWF, DIC, and upregulation of extracellular particles formation (i.e., P-selectin, and intercellular adhesion molecules, ICAM-1) $[155,165,166]$. In addition, NETs have also been identified in early phase of COVID-19, suggesting that activated neutrophils may also play a significant role in the formation of microthrombi $[167,168]$. NETs contribute to initiating the extrinsic and common pathway through elevating the activation of TF, factor XII, and platelets [169]. Therefore, CRS, elevated level of activated neutrophil, formation of NETs, and cellular activation products collectively serve as potential microthrombogenic markers of SARS-CoV-2 infection and circulating cells aggregation, resulting in generation of intra-arterial thrombus or microthrombus which is likely to contribute to the pathogenesis of arterio-micro-thrombotic diseases such as CSVD.

Of note, severe complications of COVID-19 are characterized by ARDS and pneumonia that rapidly progress to MODS. COVID-19-associated ARDS is related to endothelial dysfunction-associated vascular micro-thrombotic disease, which also involves MODS that hastens mortality in COVID-19 patients [170]. It has been proposed that these complications are secondary to COVID-19-induced endothelial dysfunction that cause the imbalance between limited vWF-cleaving protease and elevated exocytosis of vWF from ECs [171, 172]. Moreover, ECs-derived ultra large vWF (ULVWF) multimers enable the recruitment of platelets and mediate microthrombogenesis within microvasculature and eventually initiate the production of large microthrombi [172, 173]. Furthermore, the microthrombi formed can be rapidly activated and further elevates the aggregation of platelets and platelets-derived microparticles (i.e., P-selectin) inducing leukocytes aggregations. These aggregates or microclots will then dislodge from ECs luminal surface into the circulation and may occlude smaller vessel distally [172].

In the case of COVID-19, several studies had reported the presence of blood clots in COVID-19 patients with cerebral ischemia in both cerebral arteries and veins [57, 62]. Xiong and colleague supported that CRS may trigger hypercoagulation cascades that lead to formation of large and small blood clots [174]. In SVD, the activated platelets and microthrombi formation would in general initiate the narrowing of the arterial wall and upregulate the proliferative arterial wall changes [175]. Platelet aggregation is also known to result in the release of vasoactive substance resulting in SMCs constrictions, hence narrowing the arterial wall $[176,177]$. Moreover, microthrombi consist of white thrombi of aggregated fibrin and platelets that narrowed the arterial lumen as evident by the intraparenchymal small vessel microclot/ microthrombosis found in cerebral ischemia or infarcts [178, 179]. Microthrombosis-mediated cerebral microcirculatory dysfunction has been suggested as an outcome of intraparenchymal small vessel dilation that compensated the reduction in perfusion from peripheral pressure of larger arteries. This occurred as a small vessel trying to optimize the dilation process to maintain the $\mathrm{CBF}$ following the arterial lumen narrowing [180].

Therefore, it is plausible to deduce that COVID-19 elicits a micro-thrombotic disease manifestation, consisting of large amounts of circulating complexes of ECs derived microthrombi, filtered or embolized in microvascular bed with a potential micro-thrombotic occlusive impact, serving plausible roles in the onset and progression of CSVD if left untreated.

\section{SARS-CoV-2 Proliferation Mediated Hypoxia Injury}

It is well known that initial SARS-CoV-2 infection infiltrates the pneumocytes resulting in hypoxia that in turn increases the risk of CVD among COVID-19 patients [52]. This is because once the virus proliferates in the lung tissues, subsequent insults are worsened by acidic interstitial inflammatory exudation and diffuse alveolar damage $[52,181]$. The latter is characterized by accumulations of hyaline along the wall of alveoli (membrane made from dead cells, proteins, and surfactant) which disrupts the alveolar gaseous exchange [181]. Consequently, these trigger the elevation of mitochondrial anaerobic metabolisms in the brain cells causing CNS hypoxia [181]. Besides, the accumulation of acids also eventually leads to altered CBF, cerebral vasodilation, and ischemia, whereby further unabated hypoxia will cause cerebral microcirculation disturbance in the brain parenchyma structure and function [181]. Inevitably, this hypoxia potentially triggers the onset of cerebral ischemia (i.e., ischemic stroke) especially in individuals with concomitant CVD risk factors. In COVID-19 patients, this hypoxic drive is likely to 
inflict further brain damage with an increased risk of fatality [182].

\section{Others: Myocardial Injury and Cerebral Hypoperfusion}

Another potential indirect infection is through cardio-embolism from SARS-CoV-2 associated with a myocardial injury. SARS-CoV-2 proliferation-associated CRS and subsequent immune responses may lead to myocardial injury by reducing the coronary blood flow, oxygen supply, and destabilized coronary plaques and elevating microthrombogenesis [182]. Furthermore, single or combination of systemic factors such as pro-inflammatory cytokines release, hypercoagulability, and complement-mediated microvascular thrombosis may also lead to endothelial dysfunction as seen with marked increases in the levels of pro-inflammatory markers and D-dimer $[49,76,183]$. The endothelial dysfunction can be further aggravated by COVID-19-mediated RAS disruption that may result in a secondary CBF dys-autoregulation [75], leading to cerebral hypoperfusion. This has been shown in CADASIL patients with COVID-19 where CSVD lesion manifested at the cerebral internal border zone, a region that is prone to hypoperfusion [184]. Locatelli and colleagues posited that CADASIL patients may suffer from a chronic cerebral hypoperfusion mainly from the disruption in the myogenic component of CBF autoregulation where SMCs become constricted or dilated in response to changes of transmural pressure [184].

\section{SARS-CoV-2 as Potential Risk for Circulating Microparticles Release}

The mechanism that causes the cerebral ischemia or the onset and progression of CSVD in patients with COVID19 remains elusive at present, although clues are linked to hyperinflammation and hypercoagulability [50]. A recent review on COVID-19 and neurovascular complication described that SARS-CoV-2 can remain in the human systemic circulation or in neurons without toxicities [59]. The abnormal proteins misfolding and aggregations caused by SARS-CoV-2 may trigger future NDD among COVID-19 patients who have recovered and discharged from intensive care [185]. The initial trigger is associated with cytokine storm, cellular activation, and hypercoagulability that inflict damages to cerebral vascular (small/large) and BBB, which in turn may result in long-term neurological sequelae. Therefore, in this section, we put forward the proposition that COVID-19 infection may also potentially mediate another detrimental pathomechanism for COVID-19-related CSVD, i.e., the extracellular circulating microparticles (MPs).

\section{Overview of Extracellular Circulating MPs}

Recently, there is an increasing interest in the identification and quantification of cellular debris such as extracellular vesicles (EVs) as biomarkers to study the natural history of development and progression of several diseases including cardio-cerebrovascular disease, cancer, metabolic disease, and blood disease (i.e., sepsis). EVs, also known as cellderived particles or extracellular particles (EPs), are anucleate phospholipid bilayer membrane released from cells with encapsulated particles such as proteins, lipids, nucleic acids, and metabolites. Flow cytometry is the most widely used method and has major advantages over the other techniques in that each EVs (and its subtypes) is interrogated individually for the identifications and quantification based on antigen expression [186]. To date, there is no consensus in the nomenclature of EVs of different sizes, composition, and origin [187]. In general, EVs can be classified into three standard categories that include exosome (the smallest EVs: $30-100 \mathrm{~nm}$ in diameter), microparticles (MPs) or ectosome (100 nm-1 $\mu \mathrm{m}$ in diameter), and apoptotic bodies (large membrane blebs: $\leq 5 \mu \mathrm{m}$ in diameter) $[188,189]$.

MPs are anucleate, small, and membrane-enclosed EPs [190-192]. Ranging from 0.1 to $1 \mu \mathrm{m}$ in diameter, MPs are derived from direct deformation of cell plasma membrane and cell membrane phospholipids exocytic blebs that are released from the cell surface by proteolytic breakdown of the cytoskeleton due to various triggered mechanisms such as virus infection, cellular activation, oxidative stress, inflammation, injury, or apoptosis. In this context, factors such as different agonists, thrombin, serine proteases, collagen, pro-inflammatory cytokines, and physiological shear stress contribute to cellular activation and further promote the secretion and aggregation of MPs [191, 193-195]. In addition, during apoptosis, the apoptosis-induced MPs release is stimulated by the caspase-mediated Rho effector protein, the "Rho-associated" coiled-coil-containing protein kinase 1 (ROCK-1), as well as by thrombin and TNF- $\alpha$ [196]. General mechanism of MPs formation and its mode of action is described in Fig. 4.

Moreover, MPs are heterogeneous and can be produced from multiple sources (or parental cells) within the blood circulation such as platelets, erythrocytes (red blood cells, RBCs), leukocytes (white blood cells, WBCs), monocytes, ECs, and SMCs [197]. Also, MPs can be found in various body fluids such as saliva, urine, bile, CSF, and synovial fluid [198]. MPs are identified by the presence of procoagulant cell surface marker phosphatidylserine positive $\left(\mathrm{PS}^{+}\right)$, although recent evidence had suggested instances of PS negative ( $\mathrm{PS}^{-}$) [199]. Moreover, in the blood circulation of healthy individuals, MPs are present in low levels, while $70-90 \%$ of MPs are represented by platelets-derived MPs (PDMPs) that could play a role in various disease 


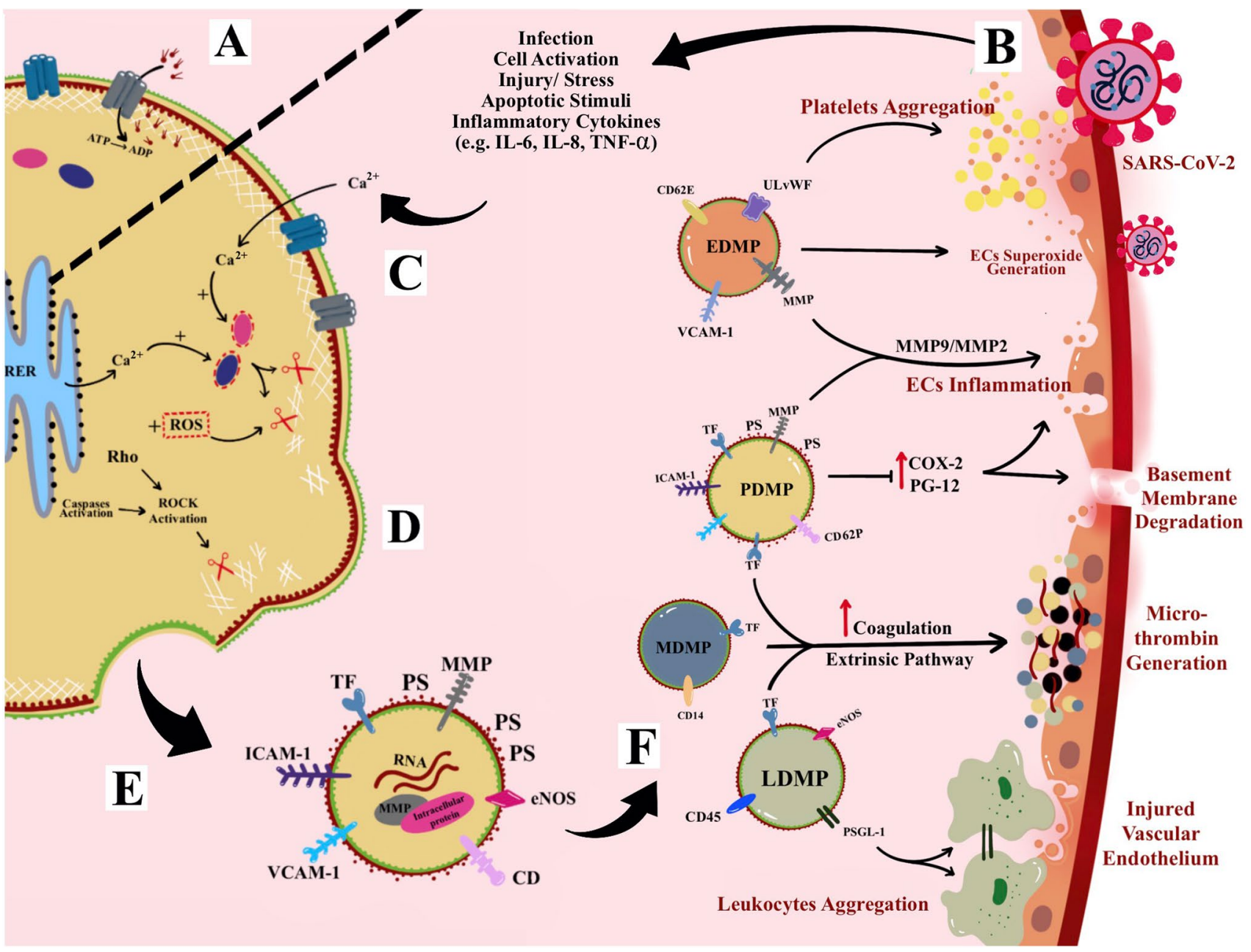

Fig. 4 Microparticles (MPs) formation and mechanism of action. A Active translocase transporting phosphatidylserine (PS) from outside to inside layer through adenosine triphosphate (ATP)-dependent manner. B Cellular activation due to infection or other cellular stressor such as increase cytokines and apoptotic stimuli. $\mathbf{C}$ The activation causes an increase in intracellular cytosolic calcium release by stress endoplasmic reticulum (ER) and acquired from extracellular space and hence activates enzymes calpain and gelsolin that cleave cell membrane cytoskeleton. D The cleaved cytoskeleton causes inactivation of translocase and, hence, induces phospholipid "flip-flopping." E Externalization of PS produces MPs that bring their parent surface

pathologies [200]. MPs composed mainly of cytosol, enclosed by globose phospholipids bilayer, whereby their cytosol may include RNAs (i.e., non-coding small interfering ribonucleic acid [siRNAs], messenger RNA [mRNA], and micro-RNA [miRNAs]) [201, 202], enzymes, and cytoskeletal proteins of their parental cells, but are anucleate and lack synthetic capacity. However, to date, there is no evidence of deoxy-ribonucleic acid (DNA) presence in MPs luminal space, although a trace of DNA has been found in exosomes and apoptotic bodies [203].

MPs carry their own parental membrane proteins or markers which are used to identify their cell of origin or molecules and protein antigens. F MPs production can trigger series of micro-thrombotic cascades. For example, leukocytes-derived MPs (PDMPs) contain P-selectin glycoprotein ligand-1 (PSGL-1) on its surface that enables leukocytes-endothelial cell (ECs) adhesion. Most MPs contain tissue factor (TF) associated with an increase in the extrinsic coagulation cascade and production of microthrombus. In fact, PDMPs and endothelial cell-derived MPs (EDMPs) may bring pro-inflammatory antigens such as matrix metalloproteinase (MMP) that can cause endotheliitis. EDMPs also possess ultra-large von Willebrand factor (ULVWF) that further assists in the recruitment and aggregation of platelets on endothelium

subpopulations. For examples, cluster differentiation 41 (CD41) is used to identify PDMPs, CD235/ CD235a for RBCs-derived MPs (RDMPs), CD31/CD146 for ECsderived MPs (EDMPs), and CD45 for leukocytes-derived MPs (LDMPs) [204]. Interestingly, PDMPs transport over 40 membrane integral protein or glycoprotein characteristic of platelets, such as integrin $\beta 1$ (CD29), $\alpha \operatorname{IIb} \beta 3$ (CD41), and P-selectin (CD62P). PDMPs and EDMPs also contain proinvasive/pro-inflammatory matrix metalloproteinase proteins (MMPs-2/9). Most of these proteins serve as adhesion molecules that stimulate the EVs internalization by these cells [200], Meanwhile, RDMPs are the smallest $(\sim 0.15 \mu \mathrm{m})$ 
compared to other cell-derived MPs whereby their surface consists of residual hemoglobin ( $20 \%$ from parent RBC) $[205,206]$.

\section{MPs Roles in Coagulation and Microthrombosis}

MPs' pro-coagulant and prothrombotic properties are partly due to their abilities to bind to sub-endothelial matrix (and its components), adhesion with soluble/non-mobile fibrinogen, as well as co-aggregation with platelet aided by a complex process involving glycoprotein (GP-IIb/ GP-IIIa) [207]. As mentioned, PS presence on MPs surface acts as pro-coagulation factors for assembly and binding agent or proteins in coagulation cascade that may lead to a prothrombotic state [193]. PS binds to hematopoietic-derived clotting factors through electrostatic interactions between phosphate groups in phospholipids and $\mathrm{Ca}^{2+}$ in gamma-carboxyglutamic (GLA) domain of clotting factors [208]. Factors VII, IX, and $\mathrm{X}$ and prothrombin are the clotting factors that contain GLA domain. Therefore, the recruitment of PS-bearing MPs and clotting factors promotes the aggregation of platelet and synthesis of fibrin which confer the propensity for the formation of microthrombus [209] that could play a plausible role in CSVD pathogenesis.

In fact, in vitro study had shown that even low levels of MPs (i.e., PDMPs and EDMPs) could induce the generation of microthrombus [210]. If compared to activated platelets (i.e., parental cells), PDMPs surfaces possess up to 100 times higher pro-coagulant properties and higher affinity binding sites for activated coagulation cascade [211]. It appears that PDMPs serve as a precursor for microthrombus formation by providing catalytic surfaces for the prothrombinase enzyme complex (i.e., involving factors IXa, Va, VIII, and Xa) [209].

Moreover, MPs also transport pro-coagulant surface TF, where MDMPs had been shown to bring an active TF that potentially elevated the extrinsic pathway involving factors VII, VIIa, IX, and X in coagulation cascade [212, 213]. As for LDMPs that express P-selectin glycoprotein ligand-1 (PSGL-1) and platelet P-selectin on their surfaces, these elements further aid the aggregation of TF bearing leukocytes at the site of vascular or microvascular injury [214]. In fact, the formation EDMPs had also been associated with elevated levels of endothelial dysfunction markers such as plasminogen activator inhibitor-1 (PAI-1) and elevated the procoagulant activity and prothrombotic state. This was due to EDMPs that contained the expression of ULVWF multimer that enabled EDMPs to induce strong platelet aggregations [215]. Thus, TF-bearing MPs may play an important role in micro- and macro-thrombus formation. In a different but related context, a study had shown that tumor cells-derived MPs bearing both $\mathrm{PS}^{+}$and TF can be utilized as reliable biomarkers to determine the risk of venous thrombosis in cancer patients [194] (Fig. 4).

\section{MPs and Inflammation}

The release of MPs into the circulation that ensued cell/ tissue inflammation can further aggravate the inflammatory activity [216]. MPs can affect microcirculation by potentiating the production and expression of pro-inflammatory cytokines, chemokines, and ICAM-1 [217] (Fig. 4). In vitro study had shown that ECs and monocytes interaction with PDMPs able to elicit the de novo expression and production of inflammatory molecule/agent such as cyclooxygenase (COX-2) and prostacyclin (PG12), respectively [218]. Another in vitro study had also shown that EDMPs are involved in the up-regulation of E-selectin, ICAM-1 and VCAM-1, and induction and release of pro-inflammatory cytokines (i.e., IL-6 and IL-8) [219].

\section{MPs and Cell Signaling}

Alongside with MPs pro-coagulant and pro-inflammatory abilities, they also serve as mediators for cell-cell interactions and signal delivery between cells. Since MPs bring along specific parental membrane receptors, cytosolic proteins, and RNAs, they can stimulate certain target cells to transform and communicate with microcirculation, in ways programmed by these surface markers [220]. For example, PDMPs can stimulate B cells to synthesize specific antibodies such as IgG by delivering CD154 IgG [221]. In addition, PDMPs assisted in monocytes to ECs interaction through ICAM-1 and hence elevated chemotaxis of monocytoid cells [218]. Furthermore, it has been shown that once PDMPs form a close contact with neutrophil, it can bind and increase neutrophil aggregations and elevate neutrophil phagocytic activity [222]. Moreover, MPs can be phagocytosed by certain cancer cells and hence stimulate the cell to induce the expression of mRNA for the pro-invasive MMP-9 and upregulate the adhesion to ECs in order to activate the ECs leading to the endothelium dysfunction. The EDMPs that expressed proteases proteins such as MMP-9 and MMP-2 enabled the invasion towards vasculature through disruption of basement membrane [223, 224] (Fig. 4).

\section{MPs and Related Clinical Syndrome}

It is well accepted that the elevated levels of MPs in blood circulation are reflective of their multi-faceted roles; for example, higher level of MPs was found in hypertensive patients [225], abdominal obesity [226], myocardial infarction [227], tumor progression and metastasis [228], atherosclerosis [229], and cardiopulmonary bypass patients [211]. Previous in vitro studies also showed that elevated T 
lymphocytes-derived MPs induced arterial endothelial dysfunction (i.e., reduce expression of NOS) in immune-compromised states [230, 231]. Moreover, MPs can also contribute to acute lung injury and inflammatory airway disease [232], with an elevated level of MDMPs being associated with upregulated pro-inflammatory IL-8, ICAM-1, MCP-1, and superoxide anion production and activation of NF- $\kappa \beta$ in monocytes [232, 233]. Besides, elevated EDMPs level has been reported to correlate with severity of endothelial dysfunction in heart diseases, i.e., coronary artery disease and acute coronary syndromes with worst clinical outcomes [192, 234, 235].

In the case of nervous system disorders, MPs had been shown to contribute to both pro- and anti- inflammatory responses in inflammation-mediated NDD including Parkinson's disease (PD), AD, amyotrophic lateral sclerosis (ALS), and dementia [236]. CNS-derived MPs had been shown to circulate in peripheral circulation and proposed to influence the cerebral immune status by transferring peripheral pro-inflammatory molecules to CNS [92, 237, 238]. Recent evidence also suggested that MPs-mediated release of pro-inflammatory cytokines, miRNAs, and microbial by-products are associated with the onset, progression, and resolution of inflammation-based cerebral injury and NDD $[239,240]$. Therefore, these associations confer circulating MPs as pertinent clinical targets and potential biomarkers of disease onset and/or progression, including that for CSVD.

\section{COVID-19 and MPs}

Viral infections are known to give rise to pathologic consequences such as thrombotic and hemorrhagic complications as seen with CVD [241, 242]. However, reports on the involvement of MPs related to COVID-19 remain scarce. Thus, bodies of evidence that may implicate MPs in the setting of COVID-19 infection are highlighted in this section.

As one of the main activators for coagulation, TF is present on the surface of certain circulating cells such as monocytes and ECs. It can also be expressed by the pathogens and inflammatory cells [243]. Moreover, the activation of ECs in viral infections may interfere in normal coagulation and fibrinolytic system, both directly and/or indirectly [244]. Viral infection initiates pro-inflammatory CRS and hence inflammation that causes imbalance in coagulation systems, resulting in coagulopathy such as thrombosis and/ or hemorrhage [245]. Furthermore, with this imbalance, further microvascular thrombosis may occur that could lead to MODS and DIC [246] as seen in an infectious disease such as malaria previously reported with a higher level of MPs [247].

A higher risk of arterial thrombosis has been documented in critically ill patients with COVID-19-based hypercoagulation, where patients developed thrombi in the lungs [50,
248]. However, it is suggested that thrombosis may well occur from the early phase of COVID-19 infection and worsened as the disease progressed [50]. Moreover, the formation and stimulation of pulmonary clots and NETs respectively halt the viral infection and further inflammation at vascular endothelium of the lungs alveolus even at an early stage [249]. These microthrombi may disseminate into the peripheral circulation and eventually aggregate to become larger thrombi within the background of untreated inflammation or CRS. Furthermore, it is known that COVID-19-based hypercoagulability are not limited to the lungs only but has been observed in the gastrointestinal tract (GIT), cerebrovascular and coronary ischemia, and even in lower limb [43, 248, $250]$, hence suggesting that the initial microthrombi produced in the lung can potentially embolize in microcirculation to settle and accumulate in distant organs.

Following viral invasion, the vascular endothelium served as the main trigger site as the general interface between immune and hemostatic systems [43]. ECs damage or activation is initiated when viruses bind to ACE2 receptor in type II pneumocyte of human lung epithelium (i.e., AT2) and myocardium, where these receptors are also highly expressed in arterial ECs [21] (Fig. 1). Once ECs are activated, they can promote an acute inflammation followed by hypercoagulation, and hence thrombosis. However, under a pulsatile shear stress condition, the increment in the ACE2 expression could promote the production of $\mathrm{NO}$ and, thus, reduce the inflammation and proliferation in vascular ECs [251]. Consequently, COVID-19 patients with heart failure or myocardial disease become more vulnerable to further infections [102]. One of the main targets of SARS-CoV-2 infection is the pericytes that surround the outer layer of ECs of capillaries and venules, reflecting the likelihood of capillary ECs dysfunction and microcirculation disturbance [102]. It has been proposed that during CRS, plasma membrane remodeling resulted in the exposure of the pro-coagulant PS, hence implicating MPs shedding in the general pathomechanism of ECs dysfunction. Moreover, pro-inflammatory factor such as TNF- $\alpha$ may also induce the production of ACE2-harbored EDMP in microvascular ECs [252]. Hence, it is plausible to posit that EDMPs-bearing ACE2 may systemically embolize from the site of formation (i.e., lung) to the distant target (i.e., brain), depositing the virus and further aggravating disease complications.

SARS-CoV-2 infection involving ECs could lead to endothelial dysfunction or endotheliitis. Therefore, measuring and enumeration of specific markers such as the selectins and MPs could prove to be beneficial to study the disease onset and progression for future prevention and therapeutic measures [50, 253]. Furthermore, MPs produced by ECs damages as a result of viral infection can further stimulate the elevation of pro-inflammatory cytokines (i.e., IL-1, IL-6, IL-8, and TNF- $\alpha$ ) [254]. Consequently, elevated levels of 
MPs can serve as a positive feedback to disease manifestation. Recently, it had also been shown that the expression of pro-inflammatory cytokines such as IL-6 and IL-8 following MPs formation can exasperate COVID-19 and been proposed to MPs (and its subpopulation) to serve as panel of markers for COVID-19 onset, progression, and severity [250].

\section{Proposition and Potential Implications for COVID-19 related MPs and Risk for CSVD}

To date, limited studies are available to implicate the role of MPs in micro-thrombosis [194] and CSVD. However, there are evidence that MPs levels are increased in patients with cardiovascular diseases and related risk factors, including acute coronary syndromes, diabetes, hypertension, and hypertriglyceridemia and the spectrum of CSVD [193, 255-257]. Table 1 summarizes the potential associations of CSVD with MPs subpopulation from published literature to date.

MPs can be formed locally or distally, and then aggregated to initiate microthrombi cascade in cerebral microvasculature (i.e., end arteries). As the microthrombogenic MPs embolized and settled at the lumen of cerebral microvasculature, they may increase the vascular tone, impair vascular relaxation, stimulate angiogenesis, and stimulate cells to produce cytokines and other inflammatory mediators as well as mediate intercellular interactions. They may also activate the formation of free radicals [261,271]. MPs are capable of these pro-coagulant effects due to the fact that they bear functionally bioactive phospholipids and cyto-adhesion molecules, such as PS and pro-coagulant TF known to play major roles as cellular activators of the coagulation cascade [194]. Moreover, the formation of MPs might contribute to the disorganization of the proper function of endothelial structural layers. For example, Martinez et al. (2011) [272] showed that endothelial dysfunction caused by MPs lowered the production of $\mathrm{NO}$ and thus induced vascular inflammation that potentially contributed to the prothrombotic state within the arterial wall and propagated atherosclerosis a hallmark of endothelial dysfunction. Besides, this dysfunction had been demonstrated to involve shedding of EDMPs that expressed platelet-ECs adhesion molecule-1 (i.e., CD31) and implicated in ischemic stroke subtypes [273]. Thus, we proposed that a targeted enumeration of MPs through peripheral venous blood in clinical setting may serve as supportive biomarker for early detection and/or prevention of CSVD, particularly among at-risk, asymptomatic individuals.

Hypercoagulability, hyperinflammation, and endotheliitis are the three prominent features of COVID-19 infection, markedly so in severe cases which affect prognosis by prothrombotic events including CSVD. Schreiber et al. (2013)
[274] also proposed another common pathomechanism of CSVD related to the disorganization of arterial segmental walls and luminal narrowing. These arose due to accumulations of MPs alongside cholesterol crystals that caused arteriolosclerosis, which may result in hypoperfusion that accompanied infarcts and WMHs [274, 275]. Besides, these features also pose added risks to the well-known features for critically ill patients (as in severe COVID-19 cases) with respiratory failure, mechanical ventilation, central venous catheter, and prolonged immobilization. Notwithstanding, the precise underlying pathomechanisms for significant cases with thrombosis associated with COVID-19, despite prophylactic and therapeutic measures, remain elusive. Hence, evidences presented here on circulating MPs offer potential implications as prognostic markers particularly in severe COVID-19 cases who are likely to be more vulnerable to MPs-mediated hypercoagulation. Moreover, in less severe or early stages of COVID-19 cases, MPs could serve as monitoring biomarkers in setting of low-grade inflammation especially those related to asymptomatic CSVD and cryptogenic stroke subtype. Essentially, such a monitoring could help mitigating the risk of such patients to develop or progress to a more severe condition.

Furthermore, there is growing body of evidence indicating the higher prevalence of COVID-19-associated small vessel stroke (i.e., cryptogenic stoke) to implicate COVID19 infection in novel small vessel stroke mechanism. For example, a recent meta-analysis study reported a fivefold increment in in-hospital mortality among a patient with COVID-19-associated stroke compared to non-COVID-19 associated [258]. In fact, to reduce the risk of mortality and progression of cryptogenic stroke, a study by the Society of Vascular and Interventional Neurology (SVIN) COVID19 multinational registry had deduced a practical approach for clinicians in dealing with COVID19-associated small or large vessel stroke (i.e., with higher CRP, white blood cell count, and D-dimer levels) to consider that the presence of 5 risk criteria such as older age, male sex, diabetes, National Institutes of Health-Stroke Scale (NIHSS) 10+, and cryptogenic stroke would imply an $80 \%$ chance of in-hospital mortality, with the risk of death with minimum of 3 criteria met [259]. Although this SVIN criteria warrant further external validation, it is useful in clinical management.

Additionally, the evidences on the use corticosteroids in the treatment for COVID-19 rest mainly on their high efficacy as an anti-inflammatory agent and therapy (i.e., in chronic inflammatory disease) [260]. Recent study also suggested the beneficial role of corticosteroids to reduce mortality in sepsis, alongside with the likely antiinflammatory actions to reduce the detrimental effects of MPs-mediated inflammation [276]. Hence, corticosteroids may indirectly aid in reducing the peripherals MPs level which in turn could prevent undesirable progression 


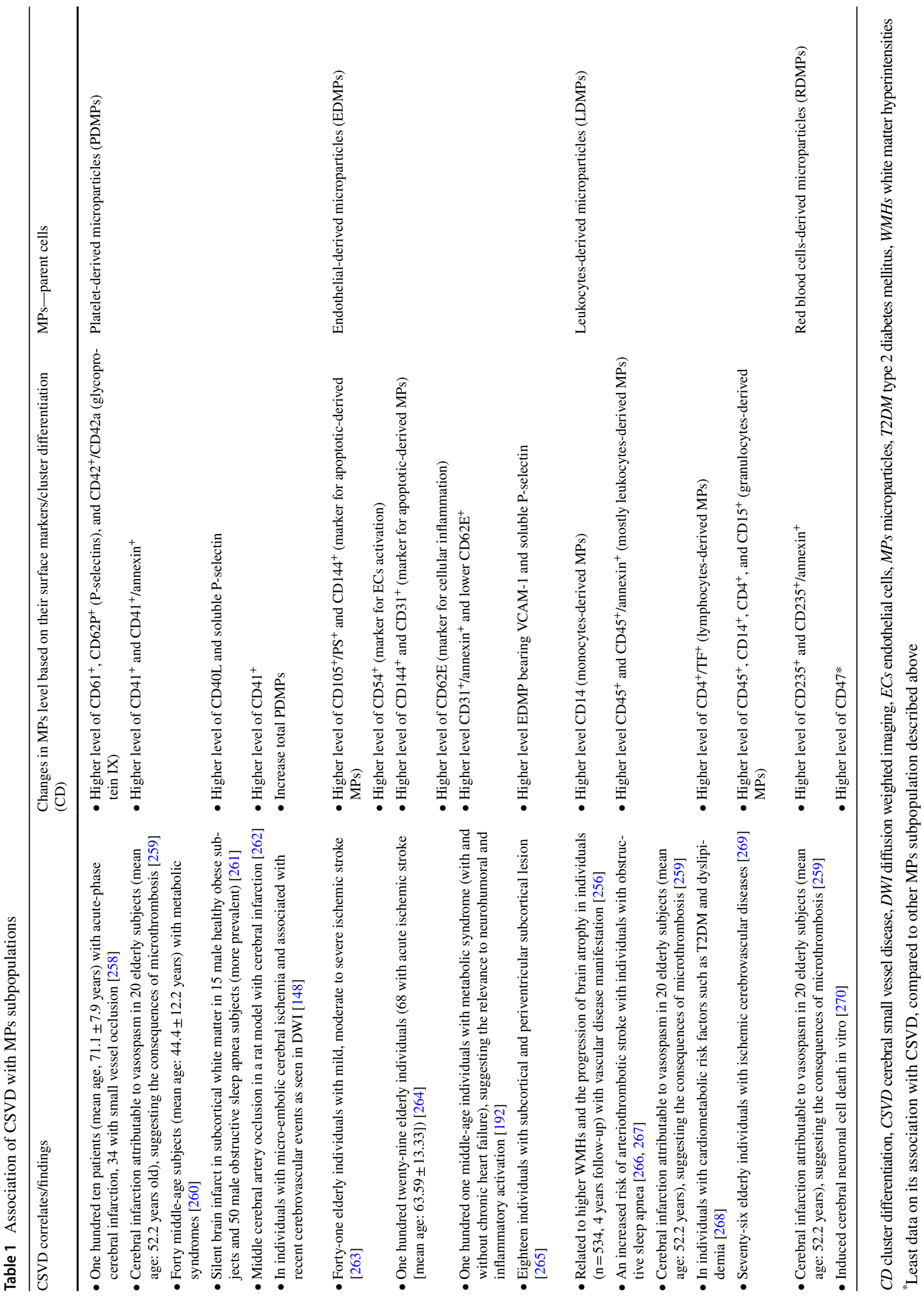


and/or further adverse effect of the infection particularly towards the onset of CSVD. In this context, another study reported that COVID-19 patients with respiratory support administered with corticosteroid therapy (namely, dexamethasone, $6 \mathrm{mg}$ per day for up to 10 days) had a reduced 28-day mortality [262]. Corroboratively, in September 2020, WHO published a guideline on the use corticosteroids for COVID-19 with a strong recommendation of systemic (i.e., intravenous, or oral) corticosteroid therapy (e.g., $6 \mathrm{mg}$ of dexamethasone orally or intravenously daily or $50 \mathrm{mg}$ of hydrocortisone intravenously every $8 \mathrm{~h}$ ) for up to 10 days in patients with severe and critical COVID19 , as well as a conditional recommendation not to use corticosteroid therapy in patients with non-severe COVID19 [263]. Nonetheless, a meta-analysis of over twenty thousand COVID-19 patients revealed a higher mortality among those who received corticosteroid therapy compared to those who did not (over 3 to 12 days treatment course). This may be due to the prothrombotic effect of the steroids which was doubled by their adverse drug reactions [264], in which the role of microthrombogenic MPs may be pertinent, albeit speculative. Thus, a rationalize use of corticosteroid is recommended to be guided by their risk-benefit ratio, whereby short course, i.e., up to 10 days therapy among a selected COVID-19 patient, may be beneficial, while an extended course may be detrimental [265].

Apart from hyperinflammation, cytokine storms mediated by hyper-coagulopathy and immunopathogenesis induced by SARS-CoV2 in vulnerable patients may lead to an increased mortality due to ARDS and MOD. Hence, the pragmatic approach such as decreasing the burden of aberrant coagulation, cytokine storm and viral loads through plasmapheresis therapy (with or without therapeutic plasma exchange [TPE]) had been reported to be beneficial in the management of COVID-19 [266]. Therapeutic plasmapheresis is the removal of abnormal accumulated substances (such as cytokines or autoantibodies) from the plasma [267]. In preclinical and/or clinical setting, the plasmapheresis can be carried out through plasma filtration (restricted to pores size of the filter-hence removal of molecules is limited) or centrifugation (unlimited removal of molecules) [268]. Besides, TPE (i.e., removal of toxins and pro-inflammatory cytokines that mediate CRS and ARDS) also has been suggested as a novel therapeutic approach for critically ill COVID-19 patients [269], whereby Zhang et al. reported that COVID19 patients administered with TPE had a reduced 28-day of mortality and higher extubation rates [270]. In this regard, as discussed, higher concentrations of pro-inflammatory cytokines at the early stage of infection and inflammation may trigger the formation of MPs (with their detrimental roles) which in turn may lead to higher chances of future COVID-19 complications. Thus, an early consideration for therapeutic plasmapheresis (with or without TPE) may afford clinicians more effectively in disease prevention and/ or progression.

At best, we have evidence to implicate multi-factorial prothrombotic states observed in COVID-19 which include heightened immuno-inflammatory responses (through mechanisms such as CRS, complement activation, endothelial injury), as well as possible contribution from systemic pressure dysregulation (RAS-related) [64, 248]. Some had suggested that SAR-CoV-2 itself can possibly activate the coagulation cascade through a mechanism that is yet to be uncovered [50, 248]. In this review, we highlight relevant evidence to relate SARS-CoV-2 infection with the risks of CSVD (both symptomatic and occult manifestations) through MPs-mediated micro- and macro-thrombosis, initiated in the peripheral (chiefly, the lungs) and potentially embolized to harm distally (i.e., the brain), or even as an in situ micro-thrombosis involving vulnerable end-arteries in cerebral microcirculation linked to CSVD.

\section{Conclusion}

MPs are pro-inflammatory, pro-coagulant membrane vesicles released by various cell types. In the setting of hemostatic imbalance such as that of COVID-19 infection, MPs are likely to be involved, even from the early sepsis as a mean to compensate for the host's systemic inflammatory response. Importantly, MPs also may induce deleterious changes in the expression of enzyme systems related to inflammation and oxidative stress which are plausible during the different phases of COVID-19 infection. In fact, MPs (i.e., EDMPs) bearing ACE2 may systemically embolize from the site of formation (i.e., lung) to the distant target (i.e., brain), hence depositing the virus and further aggravate disease complications. Given the three phases of the COVID-19 infection, it is probable that the imbalance between coagulation, inflammation, and endotheliitis could progress from physiological body defenses (in early viremia phase) to pathological hyper-reaction (in pulmonary and hyperinflammation phases). Thus, it is plausible that the thrombosis initiated by the innate immune system that aims to limit SARS-CoV-2 dissemination ends with an anomalous functioning of this system that may have contributed to the endotheliitis, resulting in loss of thrombo-protective mechanisms, excess thrombin generation, fibrinolysis dysregulation, and thrombogenesis which attract various coagulation and inflammatory players as described in this review, with a particular emphasis on the role of MPs in CSVD pathomechanism, as illustrated in Fig. 5.

In conclusion, we hypothesize that MPs-mediated microthrombogenesis may play an important role in CSVD manifestations of COVID-19 patients through the course of the infective process. Research employing comprehensive panels 


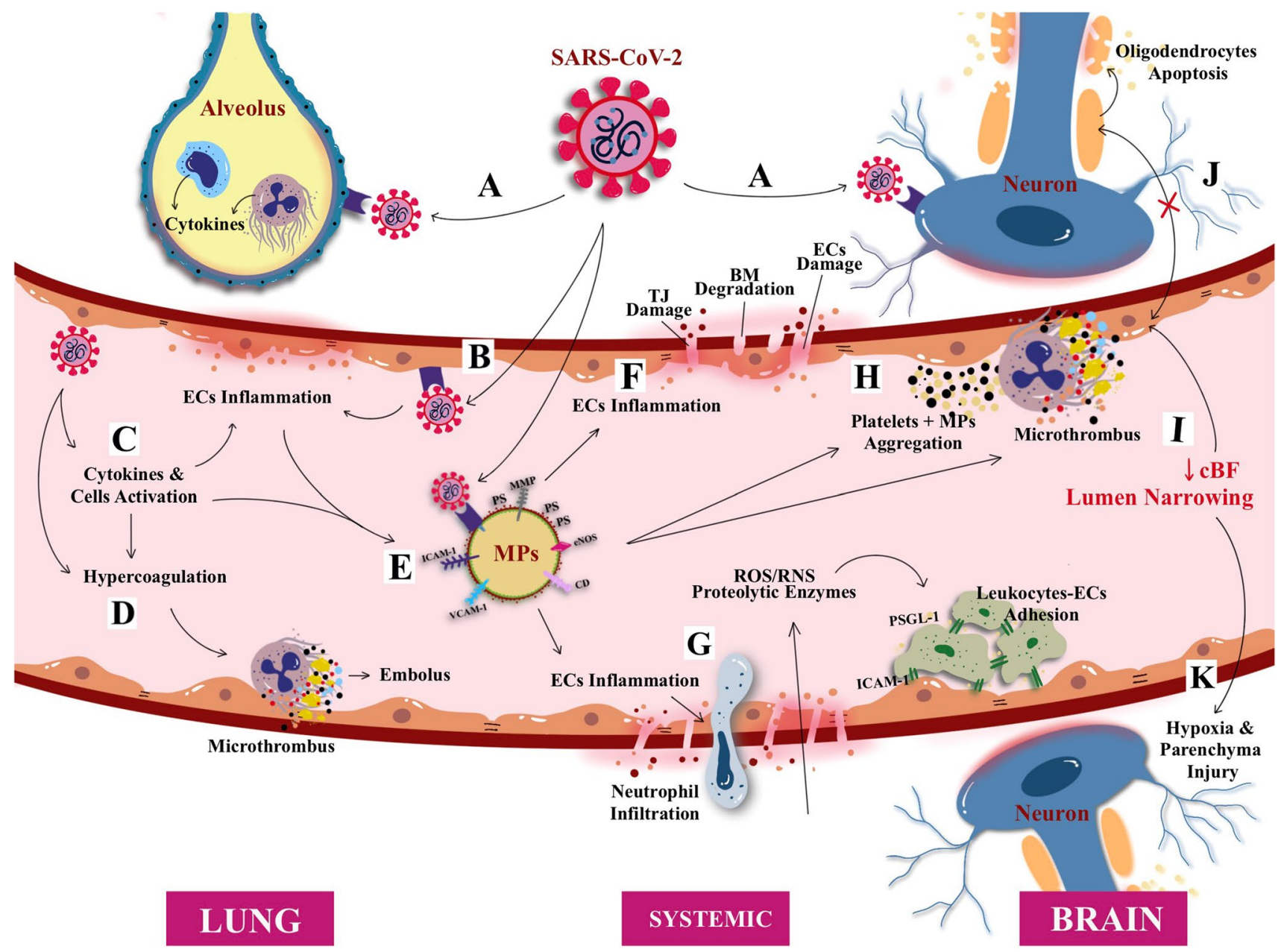

Fig. 5 Proposed interaction between COVID-19 infection and the formation of circulating microparticles (MPs) as plausible microthrombogenic risk factor for cerebral small vessel disease (CSVD) in addition to existing co-morbidity with conventional CVD risk factors-for overt symptomatic stroke events to occult (asymptomatic) manifestations. A SARS-CoV-2 infection in lung alveolus and central nervous system through angiotensin converting enzymes type 2 (ACE2) receptor present on the surface of lung alveolus and nerves cells. B SARS-CoV-2 also enters vascular microcirculation causing endothelial cells (ECs) activation and inflammation, $\mathbf{C}$ cytokines releases causing further inflammation and cellular activation and $\mathbf{D}$ hypercoagulation causing elevated clots/microthrombus formation and embolus to other organ/s. E cytokines release and cellular activation induced the formation of circulating microparticles (MPs). F MPs bring surface matrix metalloproteinase that can cause ECs inflammation and induce blood brain barrier (BBB) disruption,

of circulating MPs biomarkers for suspected and proven cases of COVID-19 may offer relevant clues to hypercoagulability and hyperinflammation states and extending this relationship to understand the manifestation of COVID19-associated CSVD as we await the world to declare an affirmative win against this unprecedented twenty-firstcentury pandemic. through (1) tight junction (TJ) damage, (2) basement membrane (BM) degradation, and (3) the EC damage and dysfunction. G BBB damage and endothelial dysfunction elevate the cellular (i.e., neutrophil) infiltration and hence increase cellular oxidative stress through increment of reactive oxygen species (ROS), reactive nitrogen species (RNS), and proteolytic enzymes, followed by leukocytes-ECs adhesion on the endothelium lining hence causing arterial wall blockage. H MPs also cause aggregation and platelet aggregations at the endothelium wall causing lumen narrowing; besides, the thrombo-emboli from microcirculation also can settle at the wall and cause blockage and narrowing of lumen and reduce cerebral blood flow (CBF). I reduced CBF and lumen narrowing can cause $\mathbf{J}$ no crosstalk between ECs and neuronal oligodendrocytes and hence cause oligodendrocytes apoptosis, i.e., demyelination disease and $\mathbf{K}$ neuronal/glial hypoxia and cerebral parenchymal injury. Thus, this emerges as a potential pathogenesis of occult CSVD

\section{Acknowledgements Not applicable.}

Author Contribution CMNCMN designed the outlines of the study, gathered the literature and resources, drafted, prepared the figures, and revised the manuscript. MM conceived the original idea, designed the outlines of the study, drafted, reviewed, and revised the manuscript. SH, WKK, SAH, NSI, NJ, and DG provided the resources, critically reviewed, revised, and improved the manuscript. All authors have read and approved the final manuscript. 
Data availability Not applicable.

\section{Declarations}

Consent to Participate Not Applicable.

Consent for Publication Not Applicable.

Conflict of Interest The authors declare no competing interests.

Open Access This article is licensed under a Creative Commons Attribution 4.0 International License, which permits use, sharing, adaptation, distribution and reproduction in any medium or format, as long as you give appropriate credit to the original author(s) and the source, provide a link to the Creative Commons licence, and indicate if changes were made. The images or other third party material in this article are included in the article's Creative Commons licence, unless indicated otherwise in a credit line to the material. If material is not included in the article's Creative Commons licence and your intended use is not permitted by statutory regulation or exceeds the permitted use, you will need to obtain permission directly from the copyright holder. To view a copy of this licence, visit http://creativecommons.org/licenses/by/4.0/.

\section{References}

1. Dhama K, Khan S, Tiwari R, Sircar S, Bhat S, Malik YS et al (2020) Coronavirus disease 2019-COVID-19. Clin Microbiol Rev 33:e00028-e120

2. Wu JT, Leung K, Bushman M, Kishore N et al (2020) Estimating clinical severity of COVID-19 from the transmission dynamics in Wuhan, China. Nat Med 26:506-510

3. COVID-19 Map (2020). Coronavirus Resource Centre, John Hopkins University (JHU). https://coronavirus.jhu.edu/map.html. Accessed Jan 15, 2021

4. Lai CC, Liu HY, Wang CY, Wang YH, Hsueh SC, Yen MY et al (2020) Asymptomatic carrier state, acute respiratory disease, and pneumonia due to severe acute respiratory syndrome coronavirus 2 (SARS-CoV-2): facts and myths. J Microbiol Immunol Infect 53(3):404-412

5. Kronbichler A, Kresse D, Yoon S, Lee KH, Effenberger M, Shin JI (2020) Asymptomatic patients as a source of COVID-19 infections: a systematic review and meta-analysis. Int J Infect Dis 98:180-186

6. Sheahan TP, Sims AC, Leist SR, Schäfer A, Won J, Brown AJ et al (2020) Comparative therapeutic efficacy of remdesivir and combination lopinavir, ritonavir, and interferon beta against MERS-CoV. Nat Commun 11:222

7. Xu Z, Shi L, Wang Y, Zhang J, Huang L, Zhang C et al (2020) Pathological findings of COVID-19 associated with acute respiratory distress syndrome. Lancet Respir Med 8:420-422

8. Shi W, Lv J, Lin L (2020) Coagulopathy in COVID-19: focus on vascular thrombotic events. J Mol Cell Cardiol 146:32-40

9. Goldberg MF, Goldberg MF, Cerejo R, Tayal AH (2020) Cerebrovascular disease in COVID-19. Am J Neuroradiol. https:// doi.org/10.3174/ajnr.A6588

10. Iadecola C (2013) The pathobiology of vascular dementia. Neuron 80(4):844-866

11. Rost NS, Etherton M (2020) Cerebral small vessel disease. Continuum (Minneap Minn) 26(2):332-352

12. Sorond FA, Cruz-Almeida Y, Clark DJ, Viswanathan A, Scherzer CR, De Jager P et al (2015) Aging, the central nervous system, and mobility in older adults: neural mechanisms of mobility impairment. J Gerontol Ser A Biol Sci Med Sci 70:1526-1532

13. Yakushiji Y, Charidimou A, Noguchi T, Nishihara M, Eriguchi M, Nanri Y et al (2018) Total small vessel disease score in neurologically healthy Japanese adults in the Kashima scan study. Int Med 57:189-196

14. Liu J, Zheng X, Tong Q, Li W, Wang B, Sutter K et al (2020) Overlapping and discrete aspects of the pathology and pathogenesis of the emerging human pathogenic coronaviruses SARSCoV, MERS-CoV, and 2019-nCoV. J Med Virol 92:491-494

15. Lam TT, Jia N, Zhang $\mathrm{Y}$ et al (2020) Identifying SARS$\mathrm{CoV}$-2-related coronaviruses in Malayan pangolins. Nature 583:282-285

16. Zhou P, Yang X, Wang X et al (2020) A pneumonia outbreak associated with a new coronavirus of probable bat origin. Nature 579:270-273

17. Tabary M, Khanmohammadi S, Araghi F, Dadkhahfar S, Tavangar SM (2020) Pathologic features of COVID-19: a concise review. Pathol Res Pract 216(9):153097

18. Li W, Zhang B, Lu J, Liu S, Chang Z, Peng C et al (2020) Characteristics of household transmission of COVID-19. Clin Infect Dis 71(8):1943-1946. https://doi.org/10.1093/cid/ciaa450

19. Romagnoli S, Peris A, Raffaele De Gaudio A, Geppetti P (2020) SARS-CoV-2 and COVID-19: from the bench to the bedside. Physiol Rev 100:1455-1466

20. Hoffmann M, Kleine-Weber H, Schroeder S, Krüger N, Herrler T, Erichsen $S$ et al (2020) SARSCoV-2 cell entry depends on ACE2 and TMPRSS 2 and is blocked by a clinically proven protease inhibitor. Cell 181:271-280.e8

21. Wang Q, Zhang Y, Wu L, Niu S, Song C, Zhang Z et al (2020) Structural and functional basis of SARS-CoV-2 entry by using human ACE2. Cell 181(4):894-904

22. Li W, Moore M, Vasilieva N et al (2003) Angiotensin-converting enzyme 2 is a functional receptor for the SARS coronavirus. Nature 426:450-454

23. Kai H, Kai M (2020) Interactions of coronaviruses with ACE2, angiotensin II, and RAS inhibitors-lessons from available evidence and insights into COVID-19. Hypertens Res 43:648-654

24. Ji H-L, Zhao R, Matalon S, Matthay MA (2020) Elevated plasmin(ogen) as a common risk factor for COVID-19 susceptibility. Physiol Rev 100:1065-1075

25. Kam YW, Okumura Y, Kido H, Ng LFP, Bruzzone R, Altmeyer $R$ (2009) Cleavage of the SARS coronavirus spike glycoprotein by airway proteases enhances virus entry into human bronchial epithelial cells in vitro. PLoS One 4:e7870

26. Devaux CA, Rolain JM, Colson P, Raoult D (2020) New insights on the antiviral effects of chloroquine against coronavirus: what to expect for COVID-19? Int J Antimicrob Agents 55:105938

27. Gattinoni L, Chiumello D, Caironi P, Busana M, Romitti F, Brazzi L, Camporota L (2020) COVID-19 pneumonia: different respiratory treatments for different phenotypes? Intensive Care Med 46(6):1099-1102

28. Chen L, Xiong J, Bao L, Shi Y (2020) Convalescent plasma as a potential therapy for COVID-19. Lancet Infect Dis 20:398-400

29. Logunov D, Dolzhikova I, Zubkova O, Tukhvatullin A, Shcheblyakov D, Dzharullaeva A et al (2020) Safety and immunogenicity of an rAd26 and rAd5 vector-based heterologous prime-boost COVID-19 vaccine in two formulations: two open, non-randomised phase 1/2 studies from Russia. The Lancet 396(10255):887-897

30. Folegatti PM, Ewer KJ et al (2020) Safety and immunogenicity of the ChAdOx $1 \mathrm{nCoV}-19$ vaccine against SARS-CoV-2: a preliminary report of a phase $1 / 2$, single-blind, randomised controlled trial. Lancet 396:467-478 
31. Baden LR, El Sahly HM, Essink B, Kotloff K, Novak FR, Diemert D et al (2021) Efficacy and safety of the mRNA-1273 SARS-CoV-2 vaccine. N Engl J Med 384(5):403-416

32. Polack FP, Thomas SJ, Kitchin N, Absalon J, Gurtman A, Lockhart S, Perez JL et al (2020) Safety and efficacy of the BNT162b2 mRNA Covid-19 vaccine. N Engl J Med 383(27):2603-2615

33. Sanders JM, Monogue ML, Jodlowski TZ, Cutrell JB (2019) Pharmacologic treatments for coronavirus disease 2019 (COVID19): a review. JAMA 323(18):1824-1836

34. Li Q, Guan X, Wu P, Wang X, Zhou L et al (2020) Early transmission dynamics in Wuhan, China, of novel coronavirus infected pneumonia. N Engl J Med 382:1199-1207

35. Arons MM, Hatfield KM, Reddy SC, Kimball A et al (2020) Public health-Seattle and King County and CDC COVID-19 investigation team. Presymptomatic SARS-CoV-2 infections and transmission in a skilled nursing facility. N Engl J Med 382:2081-2090

36. Passarelli PC, Lopez MA, Mastandrea Bonaviri GN, Garcia-Godoy F, D'Addona A (2020) Taste and smell as chemosensory dysfunctions in COVID-19 infection. Am J Dent 33(3):135-137

37. Meo SA, Alhowikan AM, Al-Khlaiwi T et al (2020) Novel coronavirus 2019-nCoV: prevalence, biological and clinical characteristics comparison with SARS-CoV and MERS-CoV. Eur Rev Med Pharmacol Sci 24(4):2012-2019

38. Lin L, Lu L, Cao W, Li T (2020) Hypothesis for potential pathogenesis of SARS-CoV-2 infection - a review of immune changes in patients with viral pneumonia. Emerg Microbes Infect 9:727-732

39. Siddiqi HK, Mehra MR (2020) COVID-19 illness in native and immunosuppressed states: a clinical-therapeutic staging proposal. J Heart Lung Transplant 39:405-407

40. Cao W, Li T (2020) COVID-19: towards understanding of pathogenesis. Cell Res 30:367-369

41. Gattinoni L, Coppola S, Cressoni M, Busana M, Rossi S, Chiumello D (2020) COVID-19 does not lead to a "typical" acute respiratory distress syndrome. Am J Respir Crit Care Med 201:1299-1300

42. Ranieri VM, Rubenfeld GD, Thompson BT, Ferguson ND, Caldwell E, Fan E et al (2012) ARDS definition task force. acute respiratory distress syndrome: the Berlin definition. JAMA 307:2526-2533

43. Varga Z, Flammer AJ, Steiger P, Haberecker M, Andermatt $\mathrm{R}$, Zinkernagel AS et al (2020) Endothelial cell infection and endotheliitis in COVID-19. Lancet 395:1417-1418

44. Channappanavar R, Perlman S (2017) Pathogenic human coronavirus infections cause and consequences of cytokine storm and immunopathology. Semin Immunopathol 39:529-539

45. Huang C, Wang Y, Li X, Ren L, Zhao J, Hu Y et al (2020) Clinical features of patients infected with 2019 novel coronavirus in Wuhan, China. Lancet 395:497-506

46. Mehta P, McAuley DF, Brown M, Sanchez E, Tattersall RS, Manson JJ, HLH Across Specialty Collaboration, UK (2020) COVID-19: consider cytokine storm syndromes and immunosuppression. Lancet 395:1033-1034

47. Wang D, Hu B, Hu C, Zhu F, Liu X, Zhang J et al (2020) Clinical characteristics of 138 hospitalized patients with 2019 novel coronavirus-infected pneumonia in Wuhan, China. JAMA 323:1061-1069

48. Zhou F, Yu T, Du R, Fan G, Liu Y, Liu Z et al (2020) Clinical course and risk factors for mortality of adult inpatients with COVID-19 in Wuhan, China: a retrospective cohort study. Lancet 395:1054-1062

49. Chen N, Zhou M, Dong X, Qu J, Gong F, Han Y et al (2020) Epidemiological and clinical characteristics of 99 cases of 2019 novel coronavirus pneumonia in Wuhan, China: a descriptive study. Lancet 395(10223):507-513

50. Thachil J (2020) The versatile heparin in COVID-19. J Thromb Haemost 18:1020-1022

51. Michalicova A, Bhide K, Bhide M, Kovac A (2017) How viruses infiltrate the central nervous system. Acta Virol 61(4):393-400

52. Wu Y, Xu X, Chen Z, Duan J, Hashimoto K, Yang L (2020) Nervous system involvement after infection with COVID-19 and other coronaviruses. Brain Behav Immun 87:18-22

53. Giacomelli A, Pezzati L, Conti F, Bernacchia D, Siano M, Oreni L et al (2020) Self-reported olfactory and taste disorders in patients with severe acute respiratory coronavirus 2 infection: a cross-sectional study. Clin Infect Dis 71(15):889-890

54. Mao L, Jin H, Wang M, Hu Y, Chen S, He Q et al (2020) Neurologic manifestations of hospitalized patients with coronavirus disease 2019 in Wuhan. China JAMA Neurol 77(6):683-690

55. Chen T, Wu D, Chen H, Yan W, Yang D, Chen G et al (2020) Clinical characteristics of 113 deceased patients with coronavirus disease 2019: retrospective study. BMJ 368:m1091

56. Phua J, Weng L, Ling L, Egi M, Lim C-M, Divatia JV et al (2020) Intensive care management of coronavirus disease 2019 (COVID-19): challenges and recommendations. Lancet Respir Med 8:506-517

57. Avula A, Nalleballe K, Narula N, Sapozhnikov S, Dandu V, Toom S et al (2020) COVID-19 presenting as stroke. Brain BEhav Immun 87:115-119

58. Troyer EA, Kohn JN, Hong S (2020) Are we facing a crashing wave of neuropsychiatric sequelae of COVID-19? Neuropsychiatric symptoms and potential immunologic mechanisms. Brain Behav Immun 87:34-39

59. Nath A (2020) Neurologic complications of coronavirus infections. Neurology 94:809-810

60. Yaghi S, Ishida K, Torres J et al (2020) SARS-CoV-2 and stroke in a New York healthcare system. Stroke 51(7):2002-2011

61. Baig AM, Khaleeq A, Ali U et al (2020) Evidence of the COVID19 virus targeting the CNS: tissue distribution, host-virus interaction, and proposed neurotropic mechanisms. ACS Chem Neurosci 11:995

62. Li YC, Bai WZ, Tsutomu H (2020) The neuroinvasive potential of SARS-CoV2 may play a role in the respiratory failure of COVID-19 patients. J Med Virol 92(6):552-555

63. Divani AA, Andalib S, Di Napoli M, Lattanzi S, Hussain MS, Biller J et al (2020) Coronavirus disease 2019 and stroke: Clinical manifestations and pathophysiological insights. J Stroke Cerebrovasc Dis 29(8):104941-104941

64. Wu C, Chen X, Cai Y, Xia J, Zhou X, Xu S et al (2020) Risk factors associated with acute respiratory distress syndrome and death in patients with coronavirus disease 2019 pneumonia in Wuhan. China JAMA Intern Med 180(7):934-943

65. Spence JD, de Freitas GR, Pettigrew LC, Ay H, Liebeskind DS, Kase CS et al (2020) Mechanism of stroke in COVID-19. Cerebrovasc Dis 49:451-458

66. Rouhl RPW, van Oostenbrugg RJ, Lodder J (2009) White matter lesions: from present to future, in Handbook of White Matter, Structure, Function and Changes, eds T. B. Westland, and R. N. Calton, (New York, NY: Nova Science Publishers), 18-19

67. Wardlaw JM, Smith C, Dichgans M (2013) Mechanisms of sporadic cerebral small vessel disease: insights from neuroimaging. Lancet Neurol 12:483-497

68. Pantoni L (2010) Cerebral small vessel disease: from pathogenesis and clinical characteristics to therapeutic challenges. Lancet Neurol 9:689-701

69. Wardlaw JM, Smith C, Dichgans M (2019) Small vessel disease: mechanisms and clinical implications. Lancet Neurol 18(7):684-696 
70. Mustapha M, Nassir CMNCM, Aminuddin N, Safri AA, Ghazali MM (2019) Cerebral small vessel disease (CSVD) - lessons from the animal models. Front Physiol 10:1317

71. Ogata J, Yamanishi H, and Ishibashi-Ueda H (2014) Pathology of cerebral small vessel disease, in Cerebral Small Vessel Disease, eds L. Pantoni, and P. Gorelick, (Cambridge: Cambridge University Press), 4-15

72. Wardlaw JM, Smith EE, Biessels GJ, Cordonnier C, Fazekas F, Frayne R et al (2013) Standards for reporting vascular changes on neuroimaging (STRIVE v1): neuroimaging standards for research into small vessel disease and its contribution to ageing and neurodegeneration. Lancet Neurol 12:822-838

73. Mahammedi A, Saba L, Vagal A, Leali M, Rossi A, Gaskill $M$ et al (2020) Imaging of neurologic disease in hospitalized patients with COVID-19: an Italian multicenter retrospective observational study. Radiol 297:E270-E273

74. Takasugi J, Miwa K, Watanabe Y, Okazaki S, Todo K, Sasaki T, Sakaguchi M, Mochizuki H (2019) Cortical cerebral microinfarcts on 3T magnetic resonance imaging in patients with carotid artery stenosis. Stroke 50(3):639-644

75. Williams OH, Mohideen S, Sen A, Martinovic O, Hart J, Brex PA (2020) Multiple internal border zone infarcts in a patient with COVID-19 and CADASIL. J Neurol Sc 416:116980

76. Oxley TJ, Mocco J, Majidi S, Kellner CP, Shoirah H, Singh IP et al (2020) Large-vessel stroke as a presenting feature of Covid19 in the young. N Engl J Med 382:e60

77. Fang L, Karakiulakis G, Roth M (2020) Are patients with hypertension and diabetes mellitus at increased risk for COVID-19 infection? Lancet Respir Med 8:e21

78. Neidich SD, Green WD, Rebeles J et al (2017) Increased risk of influenza among vaccinated adults who are obese. Int J Obes 41:1324-1330

79. Carter SJ, Baranauskas MN, Fly AD (2020) Considerations for obesity, vitamin D, and physical activity amidst the COVID-19 pandemic. Obesity 28(7):1176-1177

80. Sattar N, Mcinnes IB, Mcmurray JJV (2020) Obesity a risk factor for severe COVID-19 infection: multiple potential mechanisms. Circulation 142:4-6

81. Thuy AB, Blizzard L, Schmidt MD, Luc PH, Granger RH, Dwyer $\mathrm{T}$ (2010) The association between smoking and hypertension in a population-based sample of Vietnamese men. J Hypertens 28(2):245-250

82. Giese KA, Rost NS (2017) White matter disease. In: Sharma P, Meschia JF (eds) Stroke genetics. Springer, Basel, Switzerland, pp 191-218

83. Belani P, Schefflein J, Kihira S, Rigney B, Delman BN, Mahmoudi K (2020) COVID-19 is an independent risk factor for acute ischemic stroke. Am J Neuroradiol. https://doi.org/10. 3174/ajnr.A6650

84. Moriguchi T, Harii N, Goto J, Harada D, Sugawara H, Takamino $\mathrm{J}$ et al (2020) A first case of meningitis/ encephalitis associated with SARS-Coronavirus-2. Int J Infect Dis 94:55-58

85. Frisullo G, Bellavia S, Scala I, Piano C, Morosetti R, Brunetti V et al (2020) Stroke and COVID19: not only a large-vessel disease. J Stroke Cerebrovasc Dis 29(10):105074

86. Hanafi R, Roger PA, Perin B, Kuchcinski G, Deleval N, Dallery $F$ et al (2020) COVID-19 neurologic complication with CNS vasculitis-like pattern. AJNR Am J Neuroradiol 41(8):1384-1387. https://doi.org/10.3174/ajnr.A6651

87. Brun G, Hak JF, Coze S, Kaphan E, Carvelli J, Girard N et al (2020) COVID-19-white matter and globus pallidum lesions: Demyelination or small-vessel vasculitis? Neurology Neuroimm Nuroinflam 7(4):e777

88. Lu Y, Li X, Geng D, Mei N, Wu PY, Huang CC et al (2020) Cerebral micro-structural in COVID-19 patients - an MRI based 3-month follow-up study. EClinicalMedicine 25:1000484
89. Cauley KA, Cataltepe O (2014) Axial diffusivity of the corona radiata correlated with ventricular size in adult hydrocephalus. Am J Roentgenol 203:170-179

90. Iadecola $\mathrm{C}$ (2017) The neurovascular unit coming of age: a journey through neurovascular coupling in health and disease. Neuron 96(1):17-42

91. Fisher CM (1965) Lacunes: small, deep cerebral infarcts. Neurology 15:774-784

92. Li Q, Yang Y, Reis C, Tao T, Li W, Li X et al (2018) Cerebral small vessel disease. Cell Transplant 27:1711-1722

93. Reddy ST, Garg T, Shah C, Nascimento FA, Imran R, Kan P (2020) Cerebrovascular disease in patients with COVID-19: a review of the literature and case series. Case Rep Neurol 12:199-209

94. Leber AL, Everhart K, Balada-Llasat JM, Cullison J, Daly J, Holt $S$ et al (2016) Multicenter evaluation of biofire filmarray meningitis/encephalitis panel for detection of bacteria, viruses, and yeast in cerebrospinal fluid specimens. J Clin Microbiol 54(9):2251-2261

95. Al-Obaidi MMJ, Bahadoran A, Wang SM, Manikam R, Raju CS, Sekaran SD (2018) Disruption of the blood brain barrier is vital property of neurotropic viral infection of the central nervous system. Acta Virol 62(1):16-27

96. Soung A, Klein RS (2018) Viral encephalitis and neurologic diseases: focus on astrocytes. Trends Mol Med 24(11):950-962

97. Swanson PA, McGavern DB (2015) Viral diseases of the central nervous system. Curr Opin Virol 11:44-54

98. Ahmad I, Rathore FA (2020) Neurological manifestations and complications of COVID-19: a literature review. J Clin Neurosc: Official J Neurosurg Soc Aus 77:8-12

99. Paniz-Mondolfi A, Bryce C, Grimes Z, Gordon RE, Reidy J, Lednicky J et al (2020) Central nervous system involvement by severe acute respiratory syndrome coronavirus-2 (SARSCoV-2). J Med Virol 92(7):699-702. https://doi.org/10.1002/ jmv. 25915

100. Xiang P, Xu XM, Gao LL, Wang HZ, Xiong HF, Li RH et al (2020) First case of 2019 novel coronavirus disease with Encephalitis. ChinaXiv T 202003:00015

101. Bohmwald K, Galvez NMS, Rios M, Kalergis AM (2018) Neurologic alterations due to respiratory virus infections. Front Cell Neurosci 12:386

102. Chen L, Li X, Chen M, Feng Y, Xiong C (2020) The ACE2 expression in human heart indicates new potential mechanism of heart injury among patients infected with SARS-CoV-2. Cardiovasc Res 116:1097-1100

103. Mcgonagle D, Sharif K, O'regan A, Bridgewood C (2020) The role of cytokines including interleukin-6 in COVID-19 induced pneumonia and macrophage activation syndrome-like disease. Autoimmun Rev 19:102537

104. Fotuhi M, Mian A, Meysami S, Raji CA (2020) Neurobiology of COVID-19. J Alzheimer's Dis 76:3-19

105. Liu B, Li M, Zhou Z, Guan X, Xiang Y (2020) Can we use interleukin-6 (IL-6) blockade for coronavirus disease 2019 (COVID19)-induced cytokine release syndrome (CRS)? J Autoimmun 111:102452

106. Muhammad S, Haasbach E, Kotchourko M, Strigli A, Krenz A, Ridder DA et al (2011) Influenza virus infection aggravates stroke outcome. Stroke 42(3):783-791

107. Spiezia L, Boscolo A, Poletto F, Cerruti L, Tiberio I, Campello E, Navalesi P, Simioni P (2020) COVID-19-related severe hypercoagulability in patients admitted to intensive care unit for acute respiratory failure. Thromb Haemost 120:998-1000

108. Shakoory B, Carcillo JA, Chatham WW, Amdur RL, Zhao H, Dinarello CA, Cron RQ, Opal SM (2016) Interleukin-1 receptor blockade is associated with reduced mortality in sepsis patients 
with features of macrophage activation syndrome: reanalysis of a prior phase III trial. Crit Care Med 44:275-281

109. Ong EZ, Chan YFZ, Leong WY, Lee NMY, Kalimuddin S, Haja Mohideen SM et al (2020) A dynamic immune response shapes COVID-19 progression. Cell Host Microbe 27:879-882

110. Cauchois R, Koubi M, Delarbre D, Manet C, Carvelli J, Blasco VB et al (2020) Early IL-1 receptor blockade in severe inflammatory respiratory failure complicating COVID-19. Proc Natl Acad Sci U S A 117:18951-18953

111. Jose RJ, Manuel A (2020) COVID-19 cytokine storm: the interplay between inflammation and coagulation. Lancet Respir Med 8:e46-e47

112. Chen X, Zhao B, Qu Y, Chen Y, Xiong J, Feng Y et al (2020) Detectable serum SARS-CoV-2 viral load (RNAaemia) is closely correlated with drastically elevated interleukin 6 (IL-6) level in critically ill COVID-19 patients. Clin Infect Dis 71(8):19371942. https://doi.org/10.1093/cid/ciaa449

113. Liu F, Li L, Xu M, Wu J, Luo D, Zhu Y et al (2020) Prognostic value of interleukin-6, C-reactive protein, and procalcitonin in patients with COVID-19. J Clin Virol 127:104370

114. Barnes TC, Anderson ME, Moots RJ (2011) The many faces of interleukin-6: the role of IL-6 in inflammation, vasculopathy, and fibrosis in systemic sclerosis. Int J Rheumatol 721608.

115. TanakaT NM, Kishimoto T (2016) Immunotherapeutic implications of IL-6 blockade for cytokine storm. Immunotherapy 8:959-970

116. Coomes EA, Haghbayan H (2020) Interleukin-6 in Covid-19: a systematic review and meta-analysis. Rev Med Virol 30(6):1-9. https://doi.org/10.1002/rmv.2141

117. De Rossi N, Scarpazza C, Filippini C, Cordioli C, Rasia S, Mancinelli CR et al (2020) Early use of low dose tocilizumab in patients with COVID-19: a retrospective cohort study with a complete follow-up. EClinicalMedicine 25:100459

118. Atal S, Fatima Z (2020) IL-6 inhibitors in the treatment of serious COVID-19: a promising therapy? Pharmaceut Med 34:223-231

119. Furlow B (2020) COVACTA trial raises questions about tocilizumab's benefit in COVID-19. Lancet Rheumatol 2(10):e592. https://doi.org/10.1016/S2665-9913(20)30313-1

120. Konsman JP, Parnet P, Dantzer R (2002) Cytokine-induced sickness behaviour: mechanisms and implications. Trends Neurosci 25:154-159

121. Skelly DT, Hennessy E, Dansereau MA, Cunningham C (2013) A systematic analysis of the peripheral and CNS effects of systemic LPS, IL-1B, TNF- $\alpha$ and IL- 6 challenges in C57BL/6 mice. PLoS ONE 8(7):e69123

122. Noz MP, ter Telgte A, Wiegertjes K, Joosten LAB, Netea MG, de Leeuw FF et al (2018) Trained immunity characteristics are associated with progressive cerebral small vessel disease. Stroke 49:2910-2917

123. Staszewski J, Skrobowska E, Piusińska-Macoch P, Brodacki B, Stępień A (2020) IL-1 $\alpha$ and IL-6 predict vascular events or death in patients with cerebral small vessel disease - data from the SHEF-CSVD study. Adv Med Sci 64(2):258-266

124. Rogers JP, Chesney E, Oliver D, Pollak TA, McGuire P, FusarPoli P et al (2020) Psychiatric and neuropsychiatric presentations associated with severe coronavirus infections: a systematic review and meta-analysis with comparison to theCOVID-19 pandemic. Lancet Psychiatry 7(7):611-627. https://doi.org/10.1016/ S2215-0366(20)30203-0

125. Grochowski C, Litak J, Kamieniak P, Maciejewski R (2018) Oxidative stress in cerebral small vessel disease Role of reactive species. Free Radic Res 52(1):1-13

126. Li H, Horke S, Förstermann U (2014) Vascular oxidative stress, nitric oxide, and atherosclerosis. Atherosclerosis 237:208-219
127. Brown DI, Griendling KK (2015) Regulation of signaling transduction by reactive oxygen species in the cardiovascular system. Circ Res 116:531-549

128. Reuter S, Gupta SC, Chaturvedi MM, Aggarwal BB (2010) Oxidative stress, inflammation, and cancer: How are they linked? Free Radic Biol Med 49:1603-1616

129. Vaziri ND, Rodrigues-Iturbe B (2006) Mechanism of disease: oxidative stress and inflammation in pathogenesis of hypertension. Nat Clin Pract Nephrol 2(10):582-593

130. Casas R, Castro-Barquero S, Estruch R, Sacanella E (2018) Nutrition and cardiovascular health. Int J Mole Sci 19:3988

131. Monaghan-Benson E, Burridge K (2009) The regulation of vascular endothelial growth factor-induced microvascular permeability requires Rac and reactive oxygen species. J Biol Chem 284:25602-25611

132. Rodrigues SF, Granger DN (2015) Blood cells and endothelial barrier function. Tissue Barr 3:e978720

133. Young VG, Halliday GM, Kril JJ (2008) Neuropathologic correlates of white matter hyperintensities. Neurology 71:804-811

134. Ihara M, Yamamoto Y (2016) Emerging evidence for pathogenesis of sporadic cerebral small vessel disease. Stroke 47:554-560

135. Rajani RM, Williams A (2017) Endothelial cell-oligodendrocyte interactions in small vessel disease and aging. Clin Sci 131:369-379

136. Wu GF, Perlman S (1999) Macrophage infiltration, but not apoptosis, is correlated with immune-mediated demyelination following murine infection with a neurotropic coronavirus. J Virol 73:8771-8780

137. Rajashekhar G, Willuweit A, Patterson CE, Sun P, Hilbig A, Breier $G$ et al (2006) Continuous endothelial cell activation increases angiogenesis: evidence for the direct role of endothelium linking angiogenesis and inflammation. J Vasc Res 43:193-204

138. Nakaji K, Ihara M, Takahashi C, Itohara S, Noda M, Takahashi $\mathrm{R}$ et al (2006) Matrix metalloproteinase-2 plays a critical role in the pathogenesis of white matter lesions after chronic cerebral hypoperfusion in rodents. Stroke 37:2816-2823

139. Cai Z, Wang C, He W, Tu H, Tang Z, Xiao M et al (2015) Cerebral small vessel disease and Alzheimer's disease. Clin Interv Aging 10:1695-1704

140. Wardlaw JM, Makin SJ, Hernández MCV, Armitage PA, Heye AK, Chappell FM et al (2017) Blood-brain barrier failure as a core mechanism in cerebral small vessel disease and dementia: evidence from a cohort study. Alzheimer's Dementia 13:634-643

141. Zhang CE, Wong SM, van de Haar HJ, Staals J, Jansen JF, Jeukens CR et al (2017) Blood-brain barrier leakage is more widespread in patients with cerebral small vessel disease. Neurology $88: 426-432$

142. Zeyda M, Stulnig TM (2009) Obesity, inflammation, and insulin resistance - a mini-review. Gerontology 55:379-386

143. Stojkovic S, Kaun C, Basilio J et al (2016) Tissue factor is induced by interleukin-33 in human endothelial cells: a new link between coagulation and inflammation. Sci Rep 6:25171

144. South K, McCulloch L, McColl BW, Elkind MSV, Allan SM, Smith CJ (2020) Preceding infection and risk of stroke: An old concept revived by the COVID-19 pandemic. Int J Stroke 15(7)

145. Ding P, Zhang S, Yu M, Feng Y, Long Q, Yang H et al (2018) IL-17A promotes the formation of deep vein thrombosis in a mouse model. Int Immunopharmacol 57:132-138

146. Horvei LD, Grimnes G, Hindberg K, Mathiesen EB, Njølstad I, Wilsgaard T et al (2016) C-reactive protein, obesity, and the risk of arterial and venous thrombosis. J Thromb Haemost 14:1561-1571 
147. Valderrama EV, Humbert K, Lord A et al (2020) Severe acute respiratory syndrome coronavirus 2 infection and ischemic stroke. Stroke 51:e124-e127

148. Palta S, Saroa R, Palta A (2014) Overview of the coagulation system. Indian J Anaesth 58:515-523

149. Previtali E, Bucciarelli P, Passamonti SM, Martinelli I (2011) Risk factors for venous and arterial thrombosis. Blood Transfus 9:120-138

150. Meybohm P, Zacharowski K, Weber CF (2013) Point-of-care coagulation management in intensive care medicine. Crit Care 17:218

151. Panova-Noeva M, Eggebrecht L, Prochaska JH, Wild PS (2019) Potential of multidimensional, largescale biodatabases to elucidate coagulation and platelet pathways as an approach towards precision medicine in thrombotic disease. Hamostaseologie 39(2): 152163

152. Connors JM, Levy JH (2020) COVID-19 and its implications for thrombosis and anticoagulation. Blood 135(23):2033-2040

153. McFadyen JD, Stevens H, Peter K (2020) The emerging threat of (Micro)Thrombosis in COVID-19 and its therapeutic implications. Cir Res 127(4):571-587

154. Maier CL, Truong AD, Auld SC, Polly DM, Tanksley CL, Duncan A (2020) COVID-19-associated hyperviscosity: a link between inflammation and thrombophilia? Lancet 395:1758-1759

155. Tang N, Li D, Wang X, Sun Z (2020) Abnormal coagulation parameters are associated with poor prognosis in patients with novel coronavirus pneumonia. J Thromb Haemost 18(4):844-847

156. Andersen KG, Rambaut A, Lipkin WI, Holmes EC, Garry RF (2020) The proximal origin of SARS-CoV-2. Nat Med 26:450-452

157. Zhang JJ, Dong X, Cao YY, Yuan YD, Yang YB, Yan YQ, Akdis CA, Gao YD (2020) Clinical characteristics of 140 patients infected with SARS-CoV-2 in Wuhan. China Allergy 75(7):1730-1741

158. Lippi G, Favaloro EJ (2020) D-dimer is associated with severity of coronavirus disease 2019: a pooled analysis. Thromb Haemost 120:876-878

159. Zhang L, Yan X, Fan Q, Liu H, Liu X, Liu Z, Zhang Z (2020) D-dimer levels on admission to predict in-hospital mortality in patients with Covid-19. J Thromb Haemost 18:1324-1329

160. Delabranche X, Helms J, Meziani F (2017) Immunohaemostasis: a new view on haemostasis during sepsis. Ann Intensive Care 7(1):117

161. Metlay JP, Waterer GW, Long AC et al (2019) Diagnosis and treatment of adults with community-acquired pneumonia An official clinical practice guideline of the American Thoracic Society and Infectious Diseases Society of America. Am J Respir Crit Care Med 200(7):e45-e67

162. Jackson SP, Darbousset R, Schoenwaelder SM (2019) Thromboinflammation: challenges of therapeutically targeting coagulation and other host defense mechanisms. Blood 133(9):906-918

163. Iba T, Levy JH (2018) Inflammation and thrombosis: roles of neutrophils, platelets and endothelial cells and their interactions in thrombus formation during sepsis. J Thromb Haemost 16(2):231-241

164. Subramaniam S, Jurk K, Hobohm L et al (2017) Distinct contributions of complement factors to platelet activation and fibrin formation in venous thrombus development. Blood 129(16):2291-2302

165. Kayal S, Jaïs JP, Aguini N, Chaudière J, Labrousse J (1998) Elevated circulating E-selectin, intercellular adhesion molecule 1 , and von Willebrand factor in patients with severe infection. Am J Respir Crit Care Med 157:776-784
166. Aird WC (2003) The role of the endothelium in severe sepsis and multiple organ dysfunction syndrome. Blood 101:3765-3777

167. Fox SE, Akmatbekov A, Harbert JL et al (2020) Pulmonary and cardiac pathology in African American patients with COVID19: an autopsy series from New Orleans. Lancet Respir Med 8(7):681-686

168. Barnes BJ, Adrover JM, Baxter-Stoltzfus A et al (2020) Targeting potential drivers of COVID-19: Neutrophil extracellular traps. J Exp Med 217:e20200652

169. Noubouossie DF, Reeves BN, Strahl BD et al (2019) Neutrophils: back in the thrombosis spotlight. Blood 133:2186-2197

170. Zaim S, Chong JH, Sankaranarayanan V, Harky A (2020) COVID-19 and multi-organ response. Curr Probl Cardiol 45(8):100618

171. Mannucci PM, Canciani MT, Forza I, Lussana F, Lattuada A, Rossi E (2001) Changes in health and disease of the metalloprotease that cleaves von Willebrand factor. Blood 98(9):2730-2735

172. Bernardo A, Ball C, Nolasco L, Choi H, Moake JL, Dong JF (2005) Platelets adhered to endothelial cell-bound ultra-large von Willebrand factor strings support leukocyte tethering and rolling under high shear stress. J Thromb Haemost 3(3):562-570

173. Dong JF, Moake JL, Nolasco L et al (2002) ADAMTS-13 rapidly cleaves newly secreted ultralarge von Willebrand factor multimers on the endothelial surface under flowing conditions. Blood 100(12):4033-4039

174. Xiong M, Liang X, Wei Y (2020) Changes in blood coagulation in patients with severe coronavirus disease 2019 (COVID-19): a meta-analysis. Br J Haem 189(6):1050-1052

175. Lebas H, Yahiaoui K, Martos R, Boulaftali Y (2019) Platelets are at the nexus of vascular diseases. Front Cardiovasc Med 6:132

176. Alksne JF, Branson PJ (1980) Pathogenesis of cerebral vasospasm. Neurol Res 2(3-4):273-282

177. Asada Y, Yamashita A, Sato Y, Hatakeyama K (2020) Pathophysiology of atherothrombosis: mechanisms of thrombus formation on disrupted atherosclerotic plaques. Pat Int 70(6):309-322

178. Suzuki S, Suzuki M, Iwabuchi T, Kamata Y (1983) Role of multiple cerebral microthrombosis in symptomatic cerebral vasospasm: with a case report. Neurosurgery 13(2):199-203

179. Stein SC, Browne KD, Chen XH, Smith DH, Graham DI (2006) Thromboembolism and delayed cerebral ischemia after subarachnoid hemorrhage: an autopsy study. Neurosurgery 59(4):781-787

180. Naraoka M, Matsuda N, Shimamura N, Asano K, Ohkuma H (2014) the role of arterioles and the microcirculation in the development of vasospasm after aneurysmal SAH. BioMed Research International 1-9.

181. Abdennour L, Zeghal C, Deme M, Puybasset L (2012) Interaction brain-lungs Ann Fr Anesth Reanim 31(6): e101-107

182. Guo T, Fan Y, Chen M, Wu X, Zhang L, He T et al (2019) Cardiovascular implications of fatal outcomes of patients with coronavirus disease 2019 (COVID-19). JAMA Cardiol 5(7):811-818

183. Beyrouti R, Adams ME, Benjamin L, Cohen H, Farmer SF, Goh YY et al (2020) Characteristics of ischaemic stroke associated with COVID-19. J Neurol Neurosurg Psychiatry 0:1-3

184. Locatelli M, Padovani A, Pezzini A (2020) Pathophysiological mechanisms and potential therapeutic targets in cerebral autosomal dominant Arteriopathy with subcortical infarcts and Leukoencephalopathy (CADASIL). Front Pharmacol 11:321

185. Lippi A, Domingues R, Setz C, Outeiro TF, Krisko A (2020) SARS-cov-2: at the crossroad between aging and neurodegeneration. Mov Disord 35:716-720

186. Lacroix R, Robert S, Poncelet P, Kashturi RS, Key NS, Dignat-George F (2010) Standardization of platelet-derived microparticle enumeration by flow cytometry with calibrated beads: results of the International Society on Thrombosis and Haemostasis SSC Collaborative workshop. Int Soc Thromb Haemst 8(11):2571-2574 
187. Théry C, Witwer KW, Aikawa E, Alcaraz MJ, Anderson JD, Andriantsitohaina R et al (2018) Minimal information for studies of extracellular vesicles 2018 (MISEV2018): a position statement of the International Society for Extracellular Vesicles and update of the MISEV2014 guidelines. J Extracell Vesicles $7: 1535750$

188. Turturici G, Tinnirello R, Sconzo G, Geraci F (2014) Extracellular membrane vesicles as a mechanism of cell to cell communication: advantages and disadvantages. Am J Physiol Cell Physiol 306(C621):633

189. Hauser P, Wang S, Didenko VV (2017) Apoptotic bodies: selective detection in extracellular vesicles. Methods Mol Biol Clifton NJ 1554:193-200

190. Dignat-George F, Boulanger CM (2011) The many faces of endothelial microparticles. Arterioscl ThromVasc Bio 31(1):27-33

191. Bebawy M, Roseblade A, Luk F, Rawling T, Ung A, Grau GE (2013) Cell-derived microparticles: new targets in the therapeutic management of disease. J Pharm Pharmaceut Sc 16(2):238-253

192. Berezin AE, Kremzer AA, Berezina TA, Martovitskaya YV (2015) Pattern of circulating microparticles in chronic heart failure patients with metabolic syndrome: relevance to neurohumoral and inflammatory activation. BBA Clin 4:69-75

193. Puddu P, Puddu GM, Cravero E, Muscari S, Muscari A (2010) The involvement of circulating microparticles in inflammation, coagulation, and cardiovascular diseases. Can J Cardiol 26(4):e140-e145

194. Owens AP, Mackman N (2011) Microparticles in hemostasis and thrombosis. Circ Res 108(10): 1284-1297

195. Nomura S, Shimizu M (2015) Clinical significance of procoagulant microparticles. J Inten Care 3(1): 1

196. Sapet C, Simoncini S, Loriod B, Puthier D, Sampol J, Nguyen C, Anfosso F et al (2006) Thrombin-induced endothelial microparticle generation: identification of a novel pathway involving ROCK-II activation by caspase-2. Blood 108(6):1868-1876

197. Flaumenhaft R, Dilks JR, Richardson J, Alden E, Patel-Hett SR, Battinelli E et al (2009) Megakaryocyte-derived microparticles: direct visualization and distinction from platelet-derived microparticles. Blood 113:1112-1121

198. Freyssinet M, Toti F (2010) Formation of procoagulant microparticles and properties. Thromb Res 125(Suppl 1):46-48

199. Latham SL, Tiberti N, Gokoolparsadh N, Holdaway K, Couraud PO, Grau GER et al (2015) Immuno-analysis of microparticles: probing at the limits of detection. Sci Rep 5:16314

200. Żmigrodzka M, Guzera M, Miśkiewicz A, Jagielski D, Winnicka A (2016) The biology of extracellular vesicles with focus on platelet microparticles and their role in cancer development and progression. Tumour Biol J Int Soc Oncodevelopmental Biol Med 37:14391-14401

201. Deregibus MC, Cantaluppi V, Calogero R, Lo Iacono M, Tetta C, Biancone L et al (2007) Endothelial progenitor cell derived microvesicles activate an angiogenic program in endothelial cells by a horizontal transfer of mRNA. Blood 110:2440-2448

202. Yuan A, Farber EL, Rapoport AL, Tejada D, Deniskin R, Akhmedov NB et al (2009) Transfer of microRNAs by embryonic stem cell microvesicles. PloS One 4:e4722

203. Kawamura Y, Yamamoto Y, Sato T-A, Ochiya T (2017) Extracellular vesicles as trans-genomic agents: Emerging roles in disease and evolution. Cancer Sci 108:824-830

204. Burnier L, Fontana P, Kwak BR, Angelillo-Scherrer A (2009) Cell-derived microparticles in haemostasis and vascular medicine. Thromb Haemost 101:439-451

205. Morel O, Jesel L, Freyssinet J-M, Toti F (2011) Cellular mechanisms underlying the formation of circulating microparticles. Arterioscler Thromb Vasc Biol 31:15-26
206. Said AS, Doctor A (2017) Influence of red blood cell-derived microparticles upon vasoregulation. Blood Transf 15(6):522-534

207. Meziani F, Tesse A, Andriantsitohaina R (2008) Microparticles are vectors of paradoxical information in vascular cells including the endothelium: role in health and diseases. Pharmacol Rep 60:75-84

208. Tavoosi N, Davis-Harrison RL, Pogorelov TV, Ohkubo YZ, Arcario MJ, Clay MC et al (2011) Molecular determinants of phospholipid synergy in blood clotting. J Biol Chem 286:23247-23253

209. Chou J, Mackmann N, Merrill-Skoloff G, Pedersen B, Furie BC, Furie B (2004) Haematopoietic cell-derived microparticle tissue factor contributes to fibrin formation during thrombus propagation. Blood 104:3190-3197

210. Berckmans RJ, Nieuwland R, Bo“ing AN, Romijn F, Hack CE, Sturk A, (2001) Cell-derived microparticles circulate in healthy humans and support low grade thrombin generation. Thromb Haemost 85:639-646

211. Nieuwland R, Berckmans RJ, Rotteveel-Eijkman RC, Maquelin KN, Roozwndaal KJ, Jansen PG et al (1997) Cell derived microparticles generated in patients during cardiopulmonary bypass are highly procoagulant. Circ 96:3534-3541

212. Mackman N, Tilley RE, Key NS (2007) Role of the extrinsic pathway of blood coagulation in hemostasis and thrombosis. Arterioscler Thromb Vasc Biol 27:1687-1693

213. Lechner D, Weltermann A (2008) Circulating tissue factorexposing microparticles. Thromb Res 122(Suppl 1):S47-54

214. Falati S, Liu Q, Gross P, Merrill-Skoloff G, Chou J, Vandendries $E$ et al (2003) Accumulation of tissue factor into developing thrombi in vivo is dependent upon microparticle P-selectin glycoprotein ligand 1 and platelet P-selectin. J Exp Med 197(11):1585-1598

215. Jy W, Jimenez JJ, Mauro LM, Horstman LL, Cheng P, Ahn ER et al (2005) Endothelial microparticles induce formation of platelet aggregates via a von Willebrand factor/ristocetin dependent pathway, rendering them resistant to dissociation. J Thromb Haemost 3:1301-1308

216. Cognasse F, Hamzeh-Cognasse H, Laradi S, Chou M, Seghatchian J, Burnouf T et al (2015) The role of microparticles in inflammation and transfusion: a concise review. Transf Aph Sc 53(2):159-167

217. Batool S, Abbasian N, Burton J, Stover C (2013) Microparticles and their roles in inflammation: a review. Open Immuno J 6(1):1-14

218. Barry OP, Pratico’ D, Savani RC, FitzGerald GA, (1998) Modulation of monocyte-endothelial cell interactions by platelet microparticles. J Clin Invest 102:136-144

219. Mesri M, Altieri DC (1999) Leukocyte microparticles stimulate endothelial cell cytokine release and tissue factor induction in a JNK1 signalling pathway. J Biol Chem 274:23111-23118

220. Ratajczak J, Wysoczynski M, Hayek F, Janowska-Wieczorek A, Ratajczak MZ (2006) Membrane-derived microvesicles: important and underappreciated mediators of cell-to-cell communication. Leuk 20:1487-1495

221. Sprague DL, Elzey BD, Crist SA, Waldschmidt TJ, Jensen RJ, Ratliff TL (2008) Platelet-mediated modulation of adaptive immunity: unique delivery of CD154 signal by platelet-derived membrane vesicles. Blood 111:5028-5036

222. Jy W, Mao WW, Horstman LL, Tao J, Ahn YS (1995) Platelet microparticles bind activate and aggregate neutrophils in vitro. Blood Cells Mol Dis 21:217-231

223. Tarabolletti G, D’Ascenzo S, Borsotti P, Gaivazzi R, Pavan A, Dolo V (2002) Shedding of matrix metalloproteinases MMP2, MMP-9, and MT1-MMP as membrane vesicle-associated components by endothelial cells. Am J Pathol 160:673-680 
224. Janowska-Wieczorek A, Wysoczynski M, Kijowski J, MarquezCurtis L, Machalinski B, Ratajczak J et al (2005) Microvesicles derived from activated platelets induce metastasis and angiogenesis in lung cancer. Int J Cancer 113:752-760

225. Preston RA, Jy W, Jimenez JJ, Mauro LM, Horstman LL, Valle M et al (1979) (2003) Effects of severe hypertension on endothelial and platelet microparticles. Hypertens Dallas Tex 41:211-217

226. Murakami T, Horigome H, Tanaka K, Nakata Y, Ohkawara K, Katayama Y et al (2007) Impact of weight reduction on production of platelet-derived microparticles and fibrinolytic parameters in obesity. Thromb Res 119:45-53

227. Jung C, Sörensson P, Saleh N, Arheden H, Rydén L, Pernow J (2012) Circulating endothelial and platelet derived microparticles reflect the size of myocardium at risk in patients with STelevation myocardial infarction. Atherosclerosis 221:226-231

228. Goubran H, Sabry W, Kotb R, Seghatchian J, Burnouf T (2015) Platelet microparticles and cancer: an intimate crosstalk. Transfus. Apher. Sci. Off. J. World Apher. Assoc Off J Eur Soc Haemapheresis 53:168-172

229. Wang Z-T, Wang Z, Hu Y-W (2016) Possible roles of platelet-derived microparticles in atherosclerosis. Atherosclerosis 248:10-16

230. Martin S, Tesse A, Hugel B, Martinez MC, Morel O, Freyssinet JM et al (2004) Shed microparticles from T lymphocytes impair endothelial function and regulate endothelial protein expression. Circu 109:1653-1659

231. Li S, Wei J, Zhang C, Li X, Meng W, Mo X et al (2016) Cellderived microparticles in patients with type 2 diabetes mellitus: a systematic review and meta-analysis. Cell Physiol Biochem Int J Exp Cell Physiol Biochem Pharmacol 39:2439-2450

232. Bardelli C, Amoruso A, Federici Canova D, Fresu L, Balbo P, Neri $T$ et al (2012) Autocrine activation of human monocyte/ macrophages by monocyte-derived microparticles and modulation by PPAR $\gamma$ ligands. Brit J Pharmacol 165(3):716-728

233. Cerri C, Chimenti D, Conti I, Neri T, Paggiaro P, Celi A (2006) Monocyte/ macrophage-derived microparticles up-regulate inflammatory mediator synthesis by human airway epithelial cells. J Immunol 177:1975-1980

234. Amabile N, Boulanger CM (2011) Circulating microparticle levels in patients with coronary artery disease: a new indicator of vulnerability? Eur Heart J 32:1958-1960

235. Sinning JM, Losch J, Walenta K, Bohm M, Nickenig G, Werner N (2011) Circulating CD31+/annexin V+ apoptotic microparticles correlate with cardiovascular outcomes. Eur Heart J 32:2034-2041

236. Mohan M, Okeoma CM, Sestak K (2020) Dietary gluten and neurodegeneration: a case for preclinical studies. Int J Mol Sci 21:5407

237. Taylor PJ, Hardy J, Fischbeck KH (2002) Toxic proteins in neurodegenerative disease. Sci 296:1991-1995

238. Gan L, Cookson MR, Petrucelli L, La Spada AR (2018) Converging pathways in neurodegeneration, from genetics to mechanisms. Nat Neurosci 21:1300-1309

239. Davis D, Yuan H, Liang F-X, Yang Y-M, Westley J, Petzold C et al (2019) Human antiviral protein MxA forms novel metastable membrane less cytoplasmic condensates exhibiting rapid reversible tonicity-driven phase transitions. J Virol 93:22

240. Welch JL, Kaddour H, Winchester L, Fletcher CV, Stapleton JT, Okeoma CM (2020) Semen extracellular vesicles from HIV-1infected individuals inhibit HIV-1 replication in vitro, and extracellular vesicles carry antiretroviral drugs in vivo. JAIDS J Acquir Immune Defic Syndr 83:90-98

241. Heyderman RS (1993) Sepsis and intravascular thrombosis. Arch Dis Child 68:621-623
242. Goeijenbier M, Van Wissen M, Van de Weg C, Jong E, Gerdes V, Meijers J, Brandjes D, Van Gorp E (2012) Review: viral infections and mechanisms of thrombosis and bleeding. J Med Virol 84(10):1680-1696

243. Van der Poll T, de Boer JD, Levi M (2011) The effect of inflammation on coagulation and vice versa. Curr Opin Infect Dis 24:273-278

244. van Gorp EC, Suharti C, ten Cate H, Dolmans WM, van der Meer JW, ten Cate JW, Brandjes DP (1999) Review: infectious diseases and coagulation disorders. J Infect Dis 180:176-186

245. Connors JM, Levy JH (2020) Thromboinflammation and the hypercoagulability of COVID-19. J Thromb Haemost 18(7):1559-1561

246. Levi M (2007) Disseminated intravascular coagulation. Crit Care Med 35:2191-2195

247. Ghosh K, Shetty S (2008) Blood coagulation in falciparum malaria - a review. Parasitol Res 102:571-576

248. van Langevelde K, Srámek A, Vincken PW, van Rooden JK, Rosendaal FR, Cannegieter SC (2013) Finding the origin of pulmonary emboli with a total-body magnetic resonance direct thrombus imaging technique. Haematologica 98(2):309-315

249. Fogarty H, Townsend L, Ni Cheallaigh C, Bergin C, MartinLoeches I, Browne P et al (2020) COVID-19 Coagulopathy in Caucasian patients. Br J Haematol 189(6):1044-1049

250. Guo D, Lv Y, Qi Y, Pan S (2020) Increased circulating microparticles and inflammatory factors aggravate coronavirus disease 2019 (COVID-19). Research Square. https://doi.org/10. 21203/rs.3.rs-19182/v1

251. Song J, Hu B, Qu H, Wang L, Huang X, Li M, Zhang M (2020) Upregulation of angiotensin converting enzyme 2 by shear stress reduced inflammation and proliferation in vascular endothelial cells. Biochem Biophys Res Commun 525(3):812-818

252. Takei Y, Yamada M, Saito K, Kameyama Y, Sugiura H, Makiguchi $\mathrm{T}$ et al (2019) Increase in circulating ACE-positive endothelial microparticles during acute lung injury. Eur Respir J 54:1801188

253. Page AV, Liles WC (2013) Biomarkers of endothelial activation/ dysfunction in infectious diseases. Virulence 4:507-516

254. Thom SR, Bhopale VM, Yu K, Huang W, Kane MA, Margolis DJ (2017) Neutrophil microparticle production and inflammasome activation by hyperglycemia due to cytoskeletal instability. J Biol Chem 292(44):18312-18324

255. Cheng X, Dong Q (2012) Potential blood biomarkers in agerelated cerebral small vessel disease. Curr Transl Geriat Exp Gerontol Rep 1(2):76-84

256. Kanhai DA, de Kleijn DP, Kappelle LJ, Uiterwaal CS, van der Graaf Y, Pasterkamp G et al (2014) Extracellular vesicle protein levels are related to brain atrophy and cerebral white matter lesions in patients with manifest vascular disease: the SMARTMR study. BMJ open 4(1):e003824

257. Vilar-Bergua A, Riba-Llena I, Nafrı'a C, Bustamante A, Llombart V, Delgado L, Montane J (2016) Blood and CSF biomarkers in brain subcortical ischemic vascular disease: involved pathways and clinical applicability. J Cereb Blood Flow Metabol 36(1):55-71

258. Katsanos AH, Palaiodimou L, Zand R et al (2020) The impact of SARS-CoV-2 on stroke epidemiology and care: a meta-analysis. Ann Neurol. https://doi.org/10.1002/ana.25967

259. Ramos-Araque ME, Siegler JE, Ribo M, Requena M, López C, de Lera M, Arenillas JF, Pérez IH, Gómez-Vicente B, Talavera B, Portela PC, Guillen AN, Urra X, Llull L, Renú A, Nguyen TN, Jillella D, Nahab F, Nogueira R, Haussen D, Then R, Thon JM, Esparragoza LR, Hernández-Pérez M, Bustamante A, Mansour OY, Megahed M, Hassan T, Liebeskind DS, Hassan A, Bushnaq S, Osman M, Vazquez AR, SVIN Multinational Registry and 
Task Force (2021) Stroke etiologies in patients with COVID19: the SVIN COVID-19 multinational registry. BMC Neurol 21(1):43. https://doi.org/10.1186/s12883-021-02075-1

260. Barnes PJ (2006) How corticosteroids control inflammation: Quintiles Prize Lecture 2005. Br J Pharmacol 148:245-254. https://doi.org/10.1038/sj.bjp.0706736

261. Amabile N, Rautou PE, Tedgui A, Boulanger CM (2010) Microparticles: key protagonists in cardiovascular disorders. Sem Thromb Haemo 36(8):907-916

262. Matthay MA, Thompson BT (2020) Dexamethasone in hospitalised patients with COVID-19: addressing uncertainties. Lancet Respir Med 8:1170-1172

263. World Health Organization (WHO), Geneva. Corticosteroids for COVID-19. Living Guidelines, 2 September 2020.

264. Cano EJ, Fuentes XF, Campioli CC et al (2020) Impact of corticosteroids in COVID-19 outcomes: systematic review and meta-analysis. Chest. https://doi.org/10.1016/j.chest.2020.10. 054

265. Mishra GP, Mulani J (2021) Corticosteroids for COVID-19: the search for an optimum duration of therapy. Lancet Respir 9:e8

266. Balagholi S, Dabbaghi R, Eshghi P, Mousavi SA, Heshmati F, Mohammadi S (2020) Potential of therapeutic plasmapheresis in treatment of COVID-19 patients: Immunopathogenesis and coagulopathy. Transfus Apher Sci 59:102993

267. Harapan H, Itoh N, Yufika A, Winardi W, Keam S, Te H, et al. Coronavirus disease 2019 (COVID-19): a literature review. J Infect Public Health 2020. Apr 8.

268. Schwartz J, Padmanabhan A, Aqui N, Balogun RA, ConnellySmith L et al (2016) Guidelines on the use of therapeutic apheresis in clinical practice-evidence-based approach from the Writing
Committee of the American Society for Apheresis: the seventh special issue. J Clin Apher 31(3):149-162

269. Keith P, Day M, Perkins L, Moyer L, Hewitt K et al (2020) A novel treatment approach to the novel coronavirus: an argument for the use of therapeutic plasma exchange for fulminant COVID19. Crit Care 24:128

270. Zhang L, Zhai H, Ma S, Chen J, Gao Y (2020) Efficacy of therapeutic plasma exchange in severe COVID-19 patients. Br J Haematol 26:181-183

271. Shantsila E, Kamphuisen P, Lip G (2010) Circulating microparticles in cardiovascular disease: implications for atherogenesis and atherothrombotic. J Throm Haem 8(11):2358-2368

272. Martinez MC, Tual-Chalot S, Leonetti D, Andriantsitohaina R (2011) Microparticles: targets and tools in cardiovascular disease. T Pharmacol Sc 32(11):659-665

273. Grammas P, Martinez J, Miller B (2011) Cerebral microvascular endothelium and the pathogenesis of neurodegenerative diseases. Exp Rev Mol Med 13:e19

274. Schreiber S, Bueche CZ, Garz C, Braun H (2013) Blood brain barrier breakdown as the starting point of cerebral small vessel disease? -New insights from a rat model. Exp Transl Stroke Med 5(1):4

275. Ogata J, Yamanishi H, Ishibashi-Ueda H (2011) Review: role of cerebral vessels in ischaemic injury of the brain. Neuropath AppNeurobiol 37(1):40-55

276. Donovan K, Shah A, Day J, McKechnie SR (2021) Adjunctive treatments for the management of septic shock - a narrative review of the current evidence. Anaesthesia. https://doi.org/10.1111/anae.15369

Publisher's Note Springer Nature remains neutral with regard to jurisdictional claims in published maps and institutional affiliations. 